\title{
How Covid-19 pandemic and partial lockdown decisions affect air quality of a city? The case of Istanbul, Turkey
}

\author{
Erkan Celik $^{1}$ D $\cdot$ Muhammet Gul $^{2}$
}

Received: 29 September 2020 / Accepted: 11 March 2021 / Published online: 24 March 2021

(c) The Author(s), under exclusive licence to Springer Nature B.V. 2021

\begin{abstract}
The world is currently struggling with a new type of coronavirus (2019-nCoV) pandemic that first appeared in Wuhan, China, and then spread to almost all countries. As in other countries of the world, public authorities in Turkey are implementing many preventive and mitigating partial lockdown (PL) actions against the virus's effects. Some decisions and policies implemented before and after March 11, 2020, when the first virus case has been identified, have reduced people and traffic circulation, which has also turned into some improvements in air quality. At this point, this study aims to investigate how this pandemic affects the air quality of a metropolis. A case study of the city of Istanbul, the most affected city with more than half of Turkey's cases, is performed. In our analysis, we observe, compare, and discuss the impact of the COVID-19 pandemic and PL decisions on Istanbul city's air quality. We consider the particulate matter $\left(\mathrm{PM}_{10}\right)$, sulfur dioxide $\left(\mathrm{SO}_{2}\right)$, carbon monoxide $(\mathrm{CO})$, nitrogen dioxide $\left(\mathrm{NO}_{2}\right)$, nitrogen oxide $(\mathrm{NO})$, nitrogen oxides $\left(\mathrm{NO}_{\mathrm{x}}\right)$, and ozone (O3) concentrations. We used data from 19 air monitoring stations (AMSs) and obtained improvements in the air quality for the pandemic period. In summary, the concentration levels in $\mathrm{PM}_{10}, \mathrm{NO}_{2}, \mathrm{NO}$, and $\mathrm{NOx}$ result in a clear decline in pandemic times compared to the normal times in Istanbul. On the other hand, a non-homogenous trend for $\mathrm{SO}_{2}$ and $\mathrm{CO}$ concentrations is observed for different AMSs. A partial increase in $\mathrm{O}_{2}$ concentration is obtained in the comparison of before and during the PL period.
\end{abstract}

Keywords Air quality · 2019-nCoV · COVID-19 · Pandemic · Partial lockdown · Istanbul

\section{Introduction}

COVID-19, a new type of coronavirus, is an infectious disease that first appeared on December 30, 2019, in a Chinese city, Wuhan (Anderson et al., 2020). The World Health Organization (WHO) later confirmed COVID-19 as a pandemic. In the period of nearly

Erkan Celik

erkancelik@istanbul.edu.tr

Muhammet Gul

erkancelik@istanbul.edu.tr

1 Department of Transportation andLogistics, Istanbul University, 34322, Avc1lar, Istanbul, Turkey

2 Department of Emergency Aid and Disaster Management, Munzur University, 62000 Tunceli, Turkey 
four months, the infection, which initially expanded with Iran, Italy, Spain, France, the UK, and the USA, is spread worldwide. As of May 22, 2020, it has caused nearly 5.2 million cases and 334,862 deaths in the world (WHO, 2020a). Similar to combatting against this pandemic through the world, Turkey continues its struggle. The mortality rate, the number of intensive care patients, and the number of intubated patients are better than the most developed countries in the world. The mortality rate was $2.8 \%$ as of May 22 (Turkey Ministry of Health, 2020). Turkey is in good condition through the world in terms of the total number of tests. This is related to Turkey's early isolation decisions and as well as the case of being prepared for such an event. These isolation measures not only made the spread of the epidemic controllable but also caused some changes that could be considered positive for the environment. Restriction measures have led to the confinement of the population, reduction in public transport, and reduction of road traffic in metropolitan cities. As a result, it has led to a significant decrease in air pollution at urban levels.

The air quality is an important indicator of urban sustainability (Borrego et al. 2006). Therefore, it is used for comparing and discussing the impact of the COVID-19 pandemic on air quality. On the other hand, poor air quality is one of the main factors that have an impact on people's health and has consequences over time (Rodríguez-Urrego \& Rodríguez-Urrego, 2020). Telemedicine and virtual care (Anthony, 2020a, 2020b; Bokolo, 2020) can help for sustainable healthcare during and/or after the COVID-19 pandemic. Although the impacts of COVID-19 on the environment are short term, the efforts can strengthen environmental sustainability (Rume \& Islam, 2020).

Istanbul is the most crowded city of Turkey. It has a nearly 15.5 million populations. Turkey's metropolitan city of Istanbul serves a great fight against coronavirus, as in other metropolises in the world.

Turkey's government has made decisions and practices in the early period of the disease. Indeed, about 35 days before the first case occurred in Turkey (March 10, 2020), flights were halted with China (February 3, 2020). Also, 15 days before the first case, the land border with its neighbor Iran was closed (February 23, 2020). On February 29, 2020, about ten days before the first case, flights to Italy, South Korea, and Iraq were stopped. This was followed by such practices of travel restrictions, curfews for some age groups, cancelation of education in schools, the transition to distance education, travel ban to all countries, and weekend curfew in metropolitan cities. Although all these restrictions force people to behave untraditionally, it yields some rejoicing results (Abdullah et al., 2020; Collivignarelli et al., 2020; Dantas et al., 2020; Kerimray et al., 2020; Li et al., 2020; Mahato et al., 2020; Muhammad et al., 2020; Nakada \& Urban, 2020; Otmani et al., 2020; Sharma et al., 2020; Tobías et al., 2020; Wang \& Su, 2020; Zhu et al., 2020). It has been demonstrated by scholars that all these restrictions cause visible improvements in air pollution for the benefit of the environment. Therefore, the main problem here is to seek answers to questions such as what the basic parameters that affect air quality are, to what extent they have changed during the normal period and COVID-19 period, and what the effect of partial and full lockdown periods on the increase and decrease of these parameters.

In the light of the research questions mentioned above, the main purpose of this study is to observe, compare, and discuss the impact of COVID-19 pandemic on the air quality of Istanbul city, considering the particulate matter $\left(\mathrm{PM}_{10}\right)$, sulfur dioxide $\left(\mathrm{SO}_{2}\right)$, carbon monoxide $(\mathrm{CO})$, sulfur dioxide $\left(\mathrm{NO}_{2}\right)$, sulfur oxide $(\mathrm{NO})$, sulfur oxides (NOx), and ozone $(\mathrm{O} 3)$ concentrations. The concentrations of $\mathrm{PM}_{10}, \mathrm{SO}_{2}, \mathrm{CO}, \mathrm{NO}_{2}, \mathrm{NO}, \mathrm{NO}_{\mathrm{x}}$, and $\mathrm{O}_{3}$ were obtained at 1-h intervals. The change of concentrations was handled by comparisons in two different time periods. While the first analysis compares the values of March 1, 2020-May 22, 2020, and the same dates from the year 2019, the second analysis 
includes the comparison of the values between March 1, 2020-April 9, 2020, and April 10, 2020-May 22, 2020. The dates of this second analysis refer to before and after the partial lockdown for Istanbul.

The remainder of this paper is organized as follows. Section 2 presents an overview of the literature in evaluating the effects of COVID-19 on the air quality of cities. Section 3 introduces the material and method. Section 4 presents results and discussion of the case study of Istanbul. The final section summarizes the conclusions and provides suggestions for future research.

\section{Background: an overview to the literature}

With this extraordinary Covid-19 event, many scholars have recently reported papers regarding the impact of this pandemic on air quality. Table 1 shows the state-of-the-art review of these studies considering some characteristics such as study outlet (journal where it published), case study city or country, parameters used to assess air quality, number of sampling locations (air monitoring stations, AMS), the novelty of the study (ultimate goals), and fundamental outputs. While some scholars design their contributions on a worldwide basis, most of the study on a single city. For example, Shrestha et al. (2020), Zambrano-Monserrate et al. (2020), Cadotte (2020), Muhammad et al. (2020), and Venter et al. (2020) studied multiple countries worldwide. Shrestha et al. (2020) investigated the effects of Covid-19 on six air pollutants $\left(\mathrm{PM}_{2.5}, \mathrm{PM}_{10}, \mathrm{O}_{3}, \mathrm{SO}_{2}, \mathrm{CO}\right.$, and $\left.\mathrm{NO}_{2}\right)$ in forty cities between February-March 2019 and 2020. They determined a reduction in the mean monthly concentrations of $\mathrm{PM}_{2.5}$ and $\mathrm{PM}_{10}$ of the year 2020 compared to 2019 in most of the cities.

In the studies of Wang et al. (2020), Fattorini and Regoli (2020), Xu et al. (2020), Setti et al. (2020), Sharma et al. (2020), Asna-ashary et al. (2020), Zhu et al. (2020), Abdullah et al. (2020) and Wang and Su (2020), a single country is handled to investigate changes of air quality against Covid-19 prevalence.

Dantas et al. (2020) discussed the impact of the quarantine measures on the air quality of Rio de Janeiro, Brazil, by comparing some air gases concentrations during the partial lockdown by comparing them with values obtained in the same period of 2019. They also analyzed the situation of the weeks before and after the virus outbreak. Ching and Kajino (2020) aim to intend to give an up-to-date glimpse of the pandemic from air quality and climate perspectives. In another study, Otmani et al. (2020) studied the impact of Covid-19 lockdown on the air quality of Salé City in Morocco. Additional examples of analysis from individual cities from the world are Bontempi (2020) for Lombardy, Italy; Mahato et al. (2020) for Delhi, India; Almond et al. (2020) for Hubei, China; Nakada and Urban (2020) for São Paulo, Brazil; Tobías et al. (2020) for Barcelona, Spain; Kerimray et al. (2020) for Almaty, Kazakhstan; and Li et al. (2020) for Yangtze River Delta Region, China. In conclusion of most of the studies, a significant improvement has been yielded on the air quality with the occurrence of Covid-19 and the partial or fully lockdown decisions of governments. In total, $60 \%$ of the reviewed studies have used $\mathrm{O}_{3}, \mathrm{PM}_{10}$, and $\mathrm{PM}_{2.5}$ as an air quality indicator to assess the effects of Covid-19. Similarly, $48 \%$ of all studies have used $\mathrm{SO}_{2}$ concentration to analyze the pandemic's effect on air quality. Regarding the number of AMS where the data are extracted from, there is no consensus between the scholars. Some of them have gathered data from one single AMS, and others benefitted from different numbers of AMSs. As an example, while in Dantas et al. (2020), three AMSs are used 


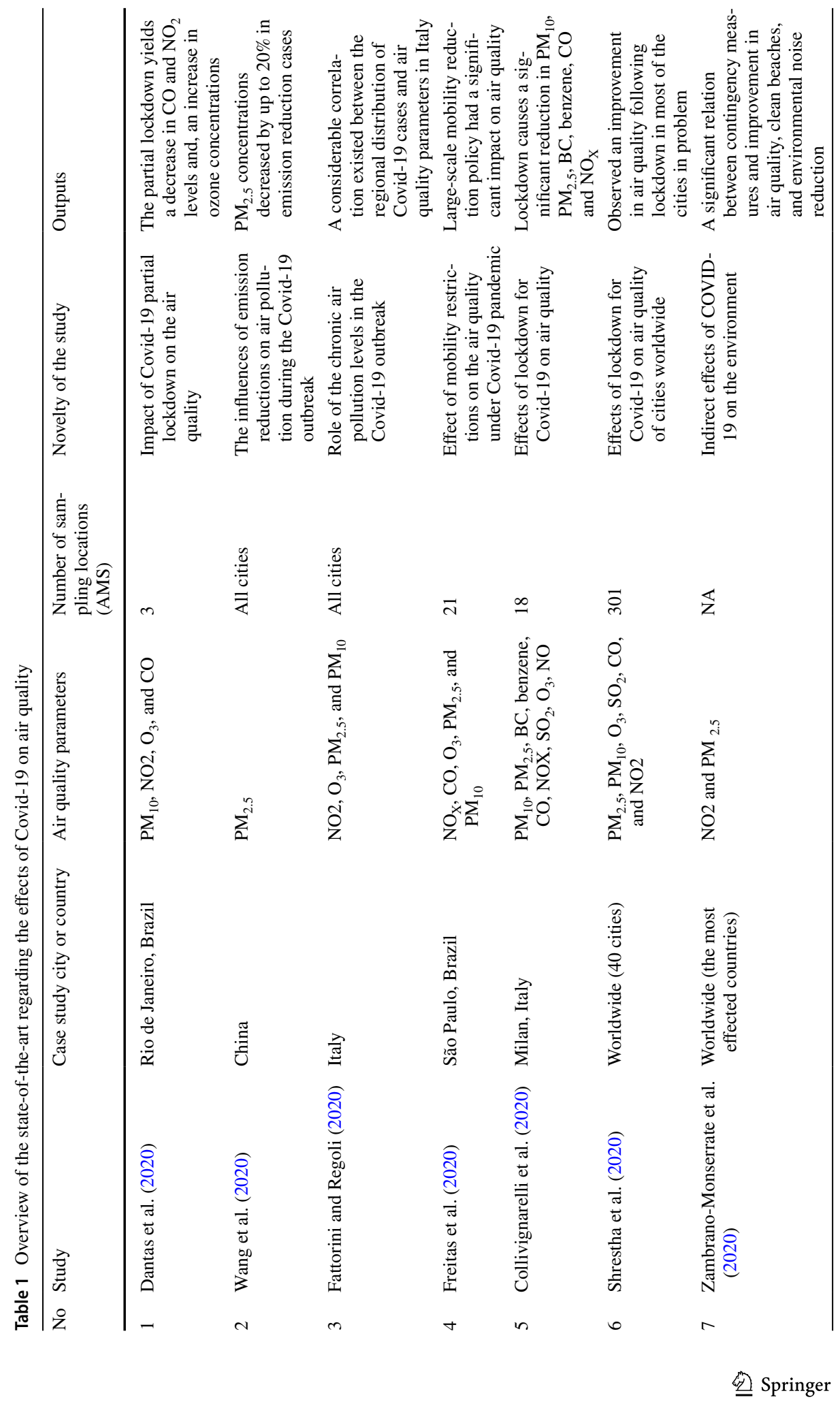




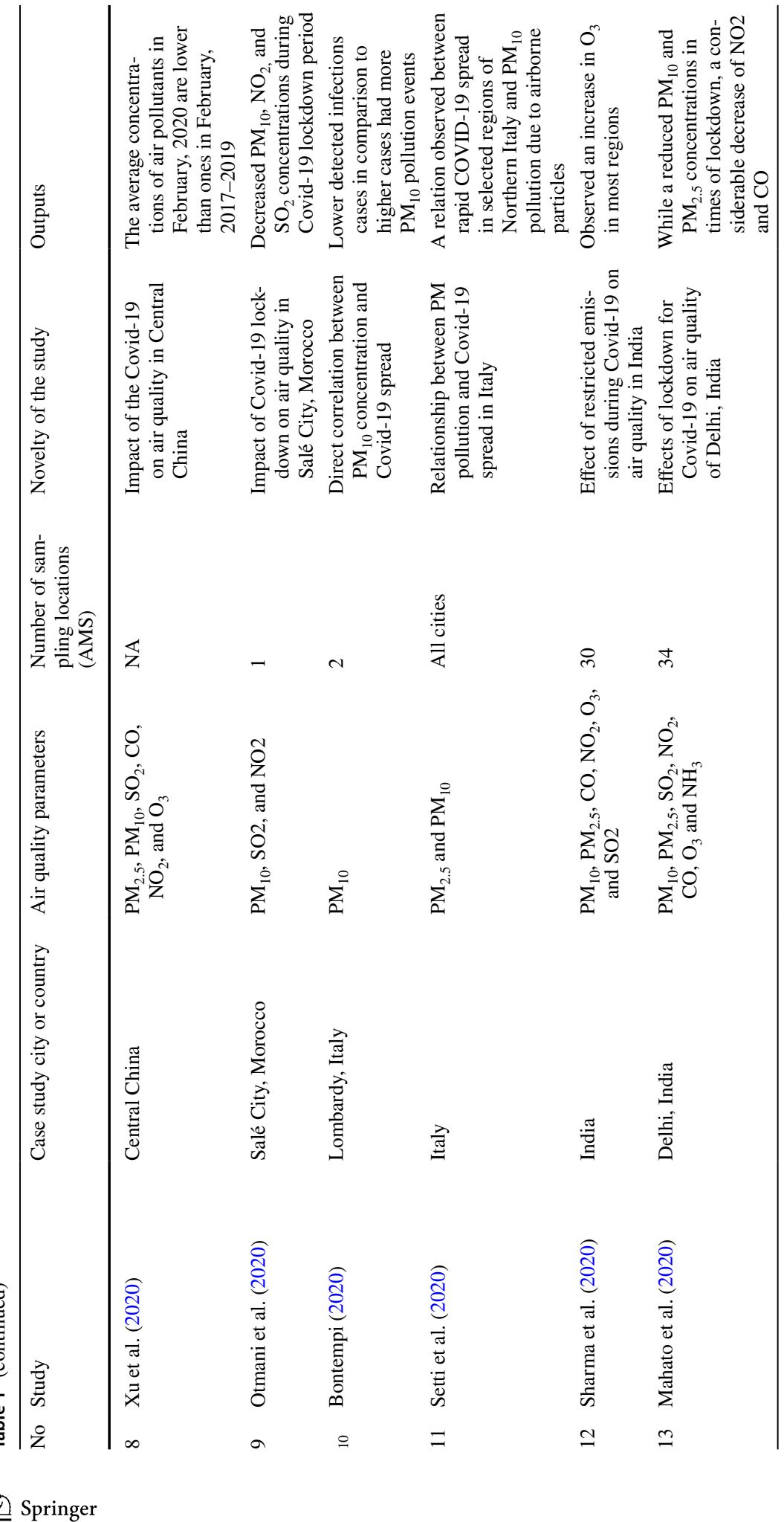




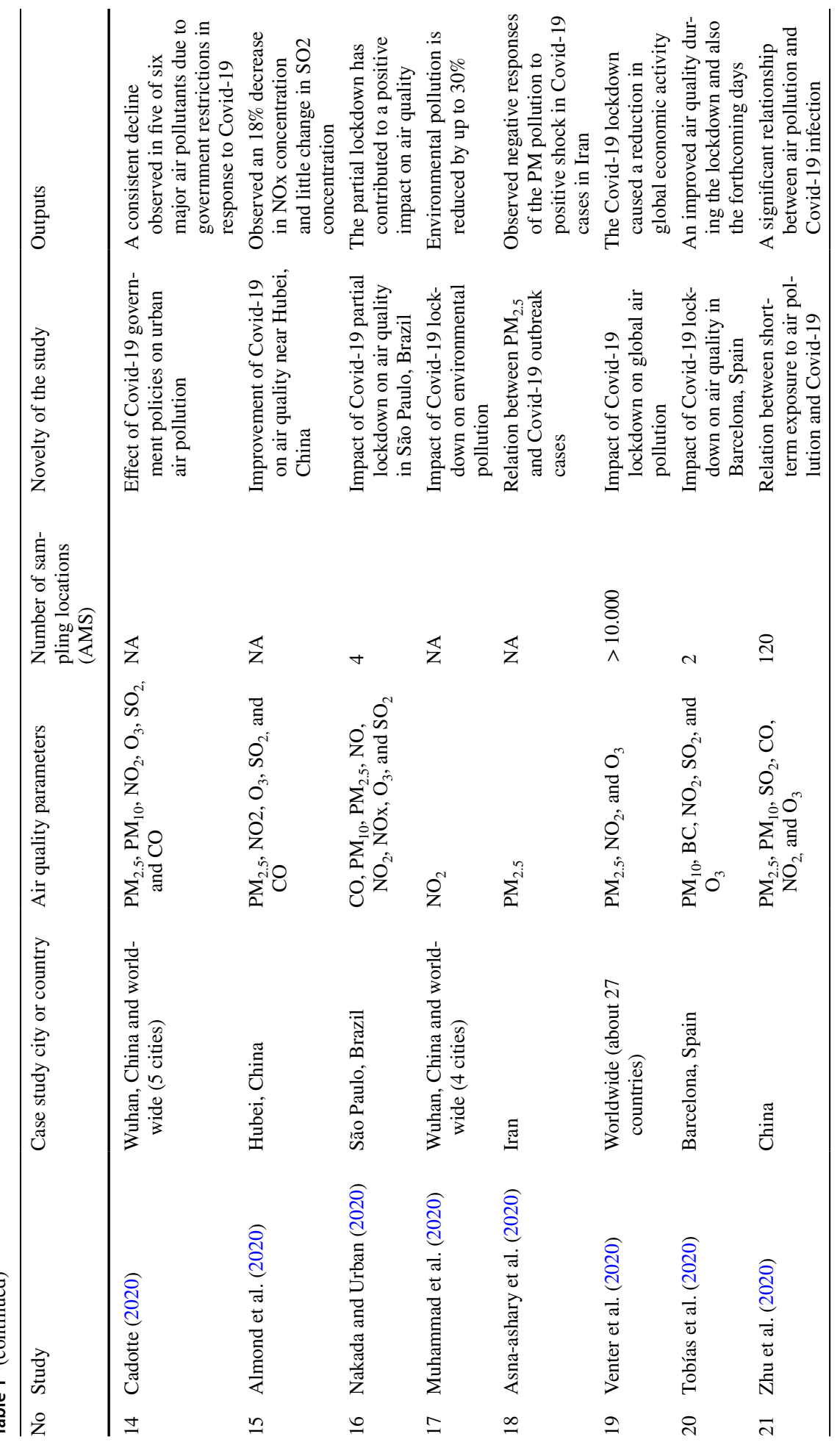




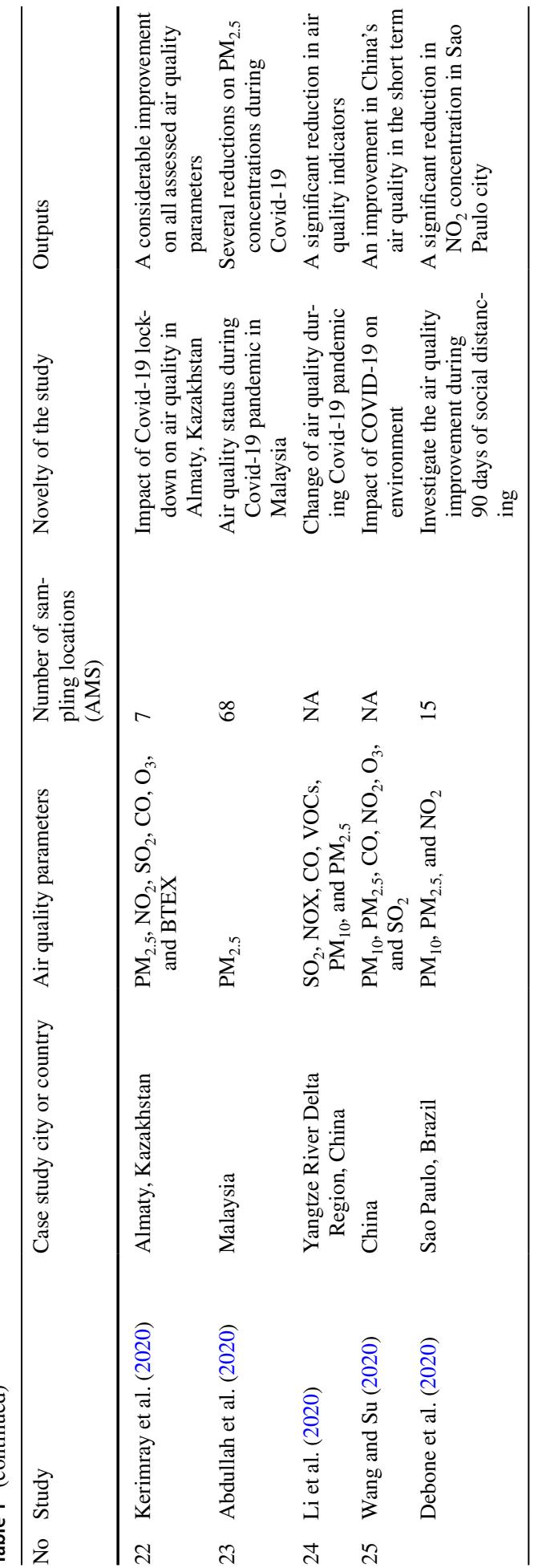


to obtain data, Freitas et al. (2020), Collivignarelli et al. (2020), and Shrestha et al. (2020) constructed their models from the data of 21,18 , and 301 sampling AMSs, respectively. More details can be found in Table 1.

In light of this state-of-the-art review mentioned above, our current study aims to seek the impacts of Covid-19 and the partial lockdown decisions on the air quality of megacity Istanbul, Turkey. For this aim, two crucial comparative work has been performed to assess the relationship, as stated in the first section.

\section{Material and method}

Istanbul is the biggest urban settlement area in Turkey. Covid-19 first case was confirmed in Istanbul, Turkey, on March 11. Turkey's largest city, Istanbul, is hosting more than half of Covid-19 cases in the country. Figure 1 demonstrates the trend that has emerged since the first case.

It has massive cultural, commercial, educational, historical, and strategical location importance (Celik et al., 2014). Istanbul plays the role of a bridge between Europe and Asia continents in many ways. Based on the data obtained from Turkish Statistical Institute (TUIK, 2020), the population of Istanbul was 15.519.267 in 2019 and Istanbul has the highest population density as well. Air pollution issues are one of the challenges of Istanbul (Baykara et al., 2019). Air pollution problems had reached significant level since 1980s, and the concentrations of the pollutant have mostly surpassed the air quality standards (Tayanç, 2000). In this study, the data were collected at 19 different AMSs (http:// www.havaizleme.gov.tr/). In total, 13 AMSs are located in Europe side of Istanbul, namely Alibeyköy, Avcılar, Aksaray, Bağcılar, Başakşehir MTHM, Beşiktaş, Esenler, Esenyurt MTHM, Kağıthane, Mecidiyeköy MTHM, Sultangazi MTHM, Silivri MTHM, Şirinevler MTHM. Six AMSs are also located in Asia side of Istanbul, namely Kadıköy, Kandilli

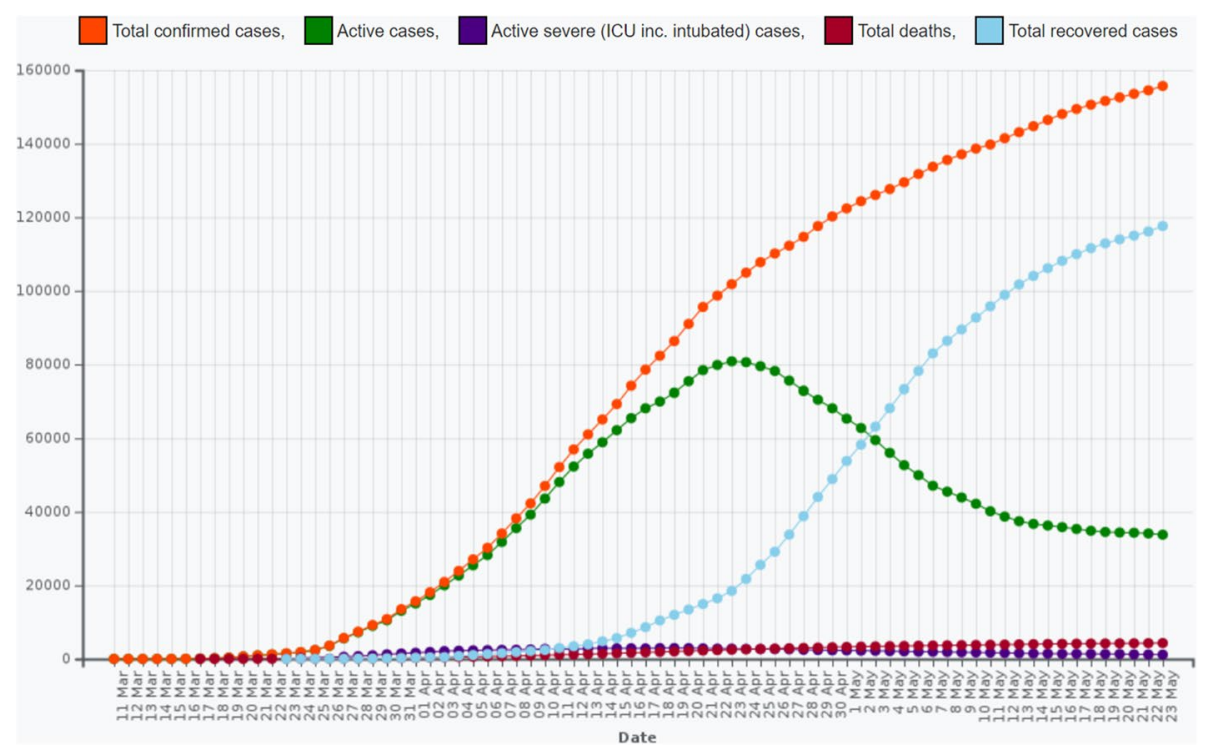

Fig. 1 Covid-19 figures of Turkey between March 10 and May 23 


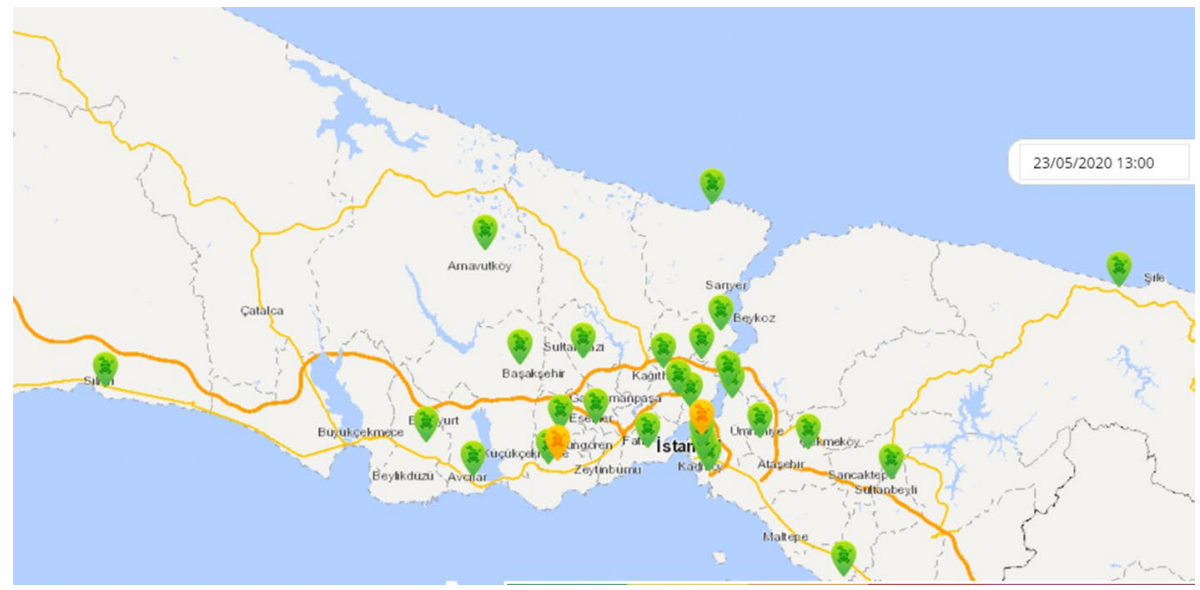

Fig. 2 The locations of all AMSs in Istanbul

MTHM, Selimiye, Sultanbeyli MTHM, Ümraniye, Üsküdar MTHM. While 9 AMSs operated by the Ministry of Environment and Urbanisation are used for this study, 10 AMSs are also operated by Istanbul Metropolitan Municipality. In this study, some AMSs are not considered because of the unavailable data and all AMSs are illustrated in Fig. 2.

The diameter of less than $10\left(\mathrm{PM}_{10}\right)$, sulfur dioxide $\left(\mathrm{SO}_{2}\right)$, carbon monoxide $(\mathrm{CO})$, nitrogen dioxide $\left(\mathrm{NO}_{2}\right)$, nitrogen oxide $(\mathrm{NO})$, nitrogen oxides $\left(\mathrm{NO}_{\mathrm{x}}\right)$, and ozone $\left(\mathrm{O}_{3}\right)$ is analyzed for the city of Istanbul, Turkey. The used parameters in 19 AMSs are presented in Table 2. In this study, two different periods are analyzed as March 1, 2019, to May 22, 2019 ( $\mathrm{n}=1992$ for each parameter and each air monitoring station), and March 1, 2020, to May 22, 2020 ( $\mathrm{n}=1992$ for each parameter each air monitoring station). The general averages are calculated for the periods previous year (March 1, 2019, to May 22, 2019) and current year (March 1, 2020, to May 22, 2020), evaluating the variation in the mean concentration $\left(\mu \mathrm{g} / \mathrm{m}^{3}\right)$ and their relative change $(\%)$ between two years. The general averages are also calculated for the periods before ( 1 March to 9 May, $n=960$ for each parameter and each station) and during the partial lockdown (10 March to 22 May, $n=1032$ for each parameter and each station), evaluating the variation in the mean concentration $\left(\mu \mathrm{g} / \mathrm{m}^{3}\right)$ between both periods and their relative change (\%).

The main reasons for selecting the city of Istanbul in this study are: (1) A significant proportion of the population in Turkey is in Istanbul, and also industrial and manufacturing facilities have intensively located around this metropolitan city. (2) The number of air monitoring stations is quite high. Compared to other cities in Turkey, access to data is easier and more systematic. (3) Undoubtedly, Istanbul is at the forefront among the cities most affected by the COVID-19 pandemic.

\section{Results and discussion}

\subsection{Particulate}

The first air pollution parameter we assessed in the air quality of the city of Istanbul, Turkey, is particulate concentration. $\mathrm{PM}_{2.5}$ particulate matter is a mixture containing organic 


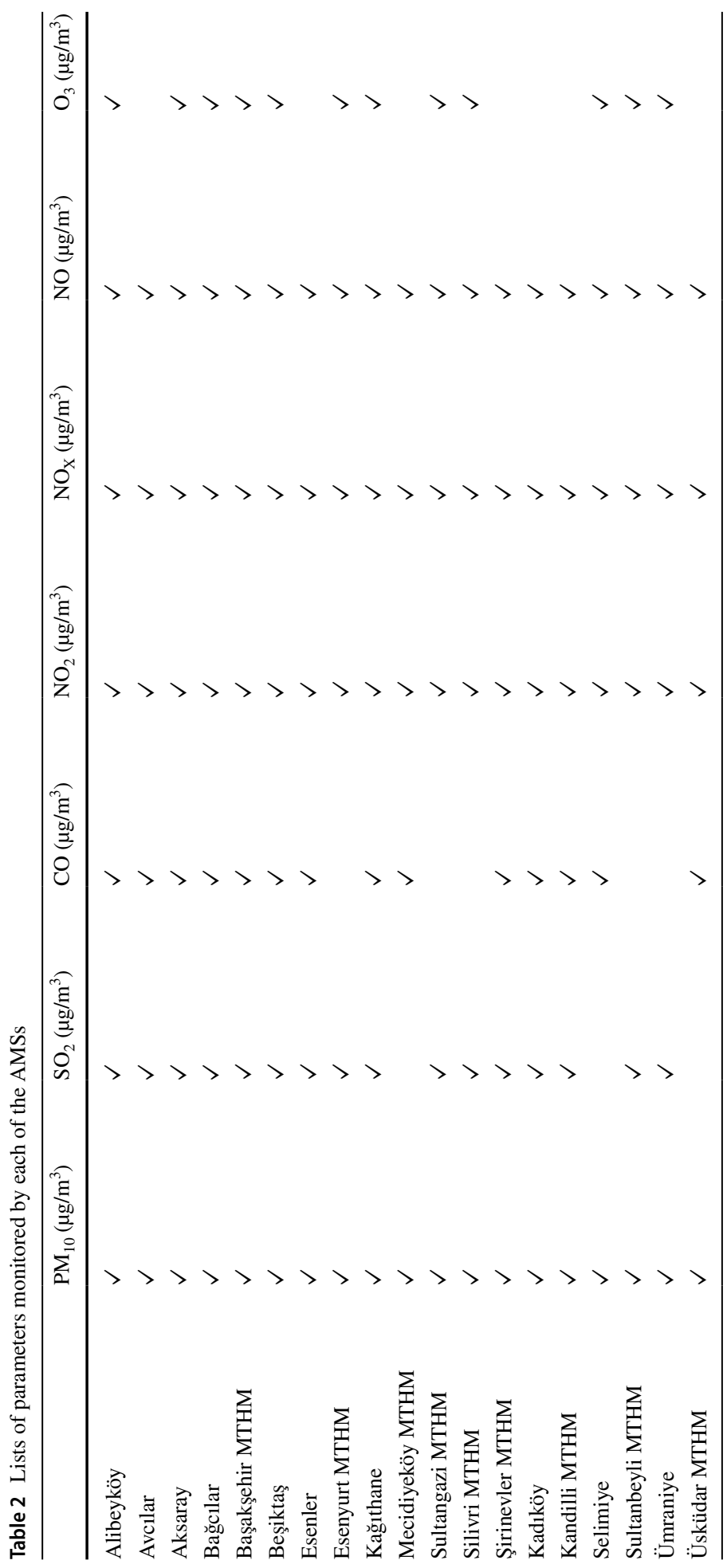


components, inorganic ions, and mineral powders. $\mathrm{PM}_{2.5}$ is defined as atmospheric particles that pose a great danger to human health and have a particle size of fewer than $2.5 \mu \mathrm{m}$. $\mathrm{PM}_{10}$, on the other hand, is defined as an atmospheric particle that is less than $10 \mu \mathrm{m}$ emerged from industrial exhaust emissions and motor vehicle exhausts and waste from fossil fuel combustion. For our case of Istanbul city, we base our results on $\mathrm{PM}_{10}$. The $\mathrm{PM}_{10}$ concentrations measured between two time periods in 19 AMSs of Istanbul are compared. These two periods are composed of the same days of the years 2019 and 2020, respectively. Therefore, we can easily observe the difference of Covid-19 effect on the air quality of the city of Istanbul. Since Istanbul is a city that has land on both the Asia and Europe sides and is located at the intersection of two continents, we have separated the results collected from the stations as Asia and Europe sides specifically for our analysis. Table 3 demonstrates the variation in $\mathrm{PM}_{10}$ concentrations for two-year comparison.

The effects of two time intervals follow a similar variation on most of the AMSs. The $\%$ variation in declining trend is measured averagely between $29.15 \%$ (Beşiktaş AMS) and $1.19 \%$ (Silivri MTHM AMS). The only exception among 19 AMSs is the average value measured from Sultanbeyli MTHM station on the Asia side. Accordingly, the value of 2019 in the relevant date range has increased slightly in 2020 (1.41\%). Also, the box plot demonstration of variation in $\mathrm{PM}_{10}$ for Aksaray AMS is provided in Fig. 3. It can be seen from Fig. 3 that the concentration of $\mathrm{PM}_{10}$, especially for Aksaray AMS, decreased during the months of April and May compared to the same months of the previous year (2019), when the national authority took measures to prevent and mitigate Covid-19 outbreaks.

The effects of before and during PL on the air quality presents a clearer picture than the first analysis above. According to this secondary analysis, the $\mathrm{PM}_{10}$ concentrations from all AMSs have an improvement. The average $\mathrm{PM}_{10}$ values measured from all AMSs between April 10, 2020, and May 22, 2020, were obtained lower than the values measured between March 1, 2020, and April 9, 2020. The \% variation ranges between 0.49\% (Avc1lar AMS) and $38.27 \%$ (Alibeyköy AMS). The reduction is directly related to the PL decision of the Turkish government. This result is attributable to the travel restrictions in Istanbul and the other 30 megacities of Turkey implemented by the public authority and the reduction in traffic flow, Table 4.

The hourly variation in $\mathrm{PM}_{10}$ concentration before and during PL measured at Aksaray AMS is shown in Fig. 4. When investigated the first time interval of Fig. 4, which corresponds to before PL, it is easily inferred that $\mathrm{PM}_{10}$ values on Fridays are peak values. It is an expected result that there will be more traffic density, especially on Fridays due to the completion of working hours and being the last of the week's working days. These peak values have considerably decreased in the times of PL against the Covid-19 pandemic. Additionally, the variability of the values seen in the plot has also been decreased. The outliers of the data are relatively less.

\subsection{Sulfur dioxide}

$\mathrm{SO}_{2}$ is a gas like other parameters used in determining air quality. The majority of $\mathrm{SO}_{2}$ in the air is of human origin. Wastes from industrial plants and motor vehicle emissions can be shown as the main source of this gas. Generally, it is expected to decrease $\mathrm{SO}_{2}$ value in times of Covid-19 outbreak compared to the normal times. In the literature, Tobías et al. (2020) obtained a difference (19.4\% decrease, $1.8 \%$ increase) in $\mathrm{SO}_{2}$ level between before and during the lockdown in urban background and traffic, respectively. In Istanbul's figures, it seems that there is an irregular variation (Table 5). 


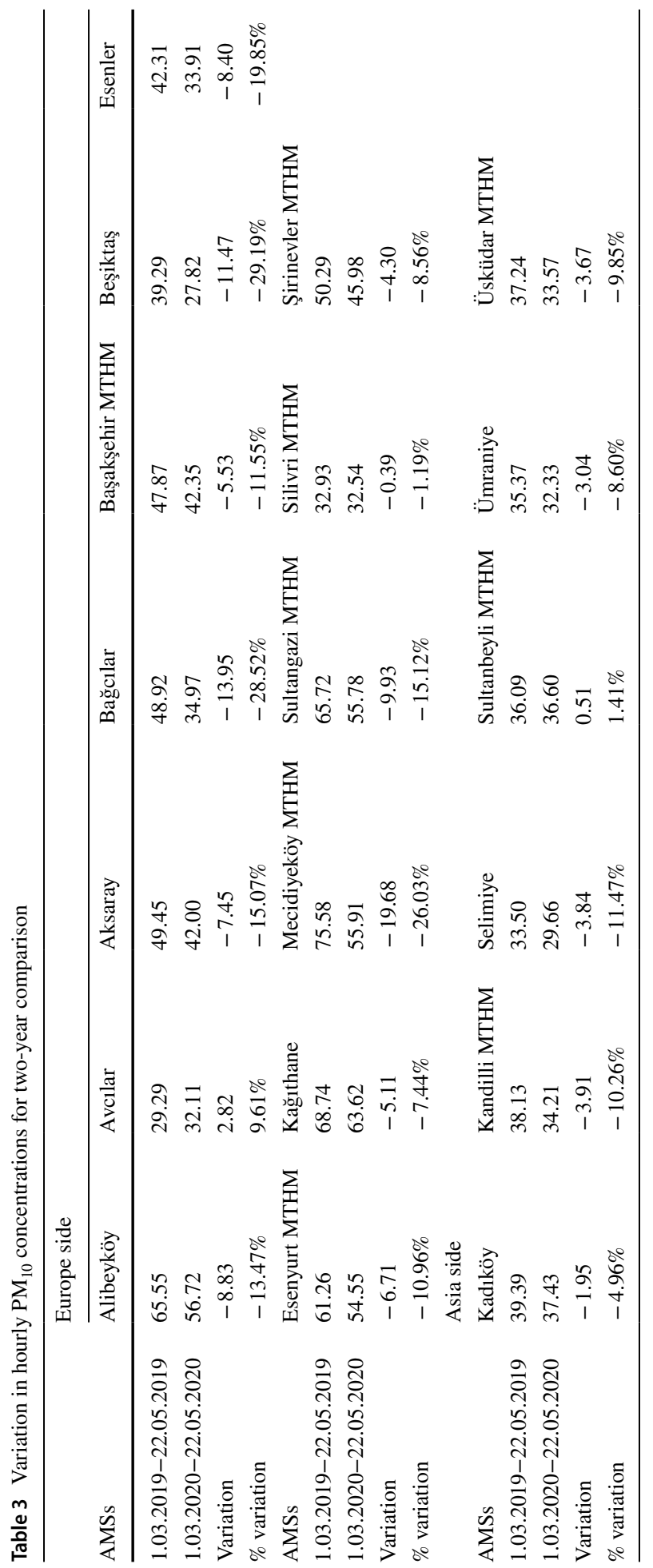




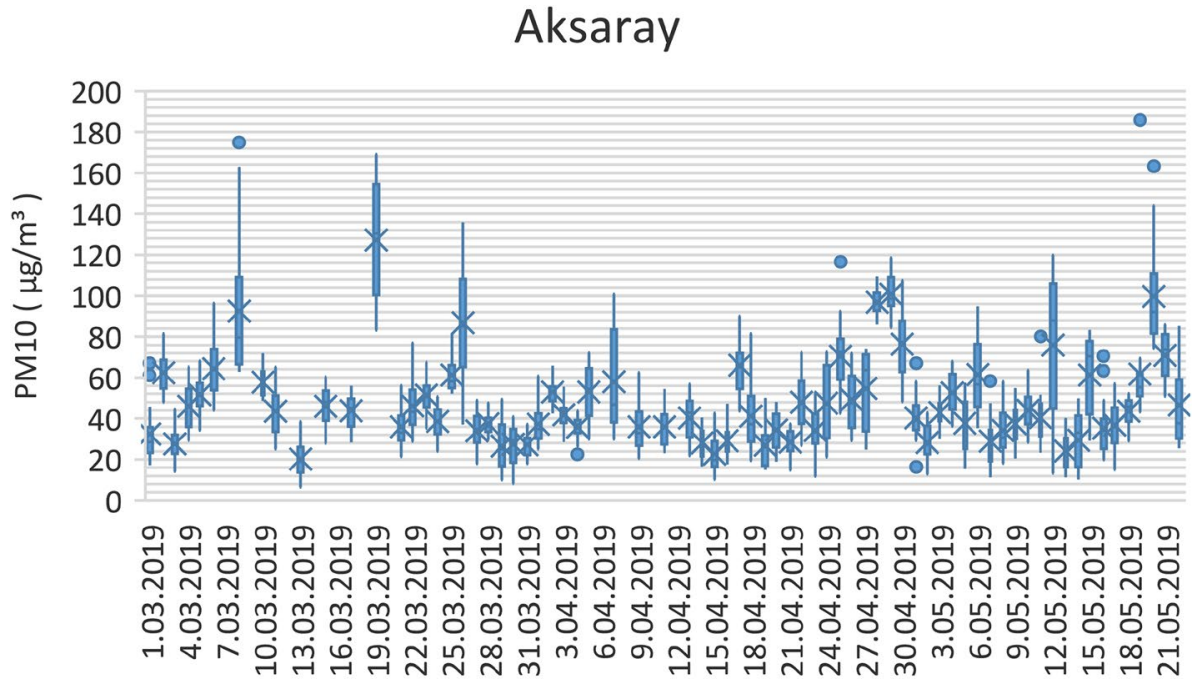

1.03.2019-22.05.2019

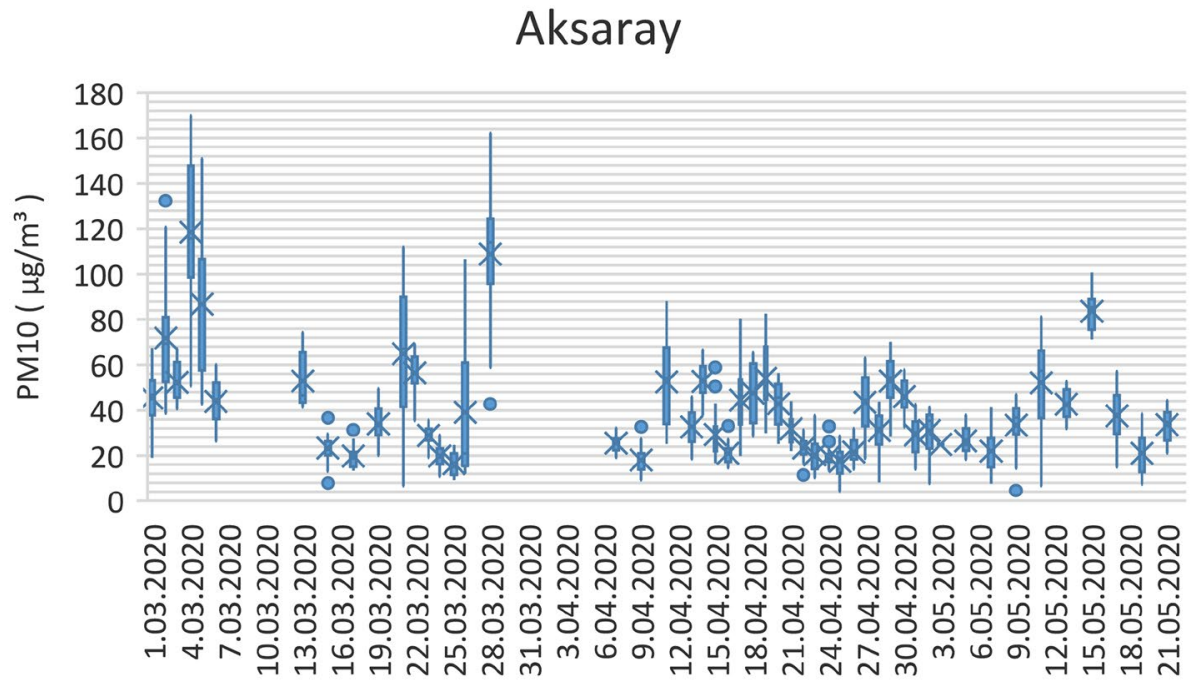

\subsubsection{0-22.05.2020}

Fig. 3 The variation in $\mathrm{PM}_{10}$ for Aksaray AMS for two-year comparison

Table 5 demonstrates that while a higher variation has existed in some AMSs, it is observed a more reasonable change in some AMSs. For example, half of the AMSs in Europe side of Istanbul has a negative \% variation in $\mathrm{SO}_{2}$ level such as Avcılar, Aksaray, Bağcılar, Beşiktaş, Esenyurt MTHM, and Silivri MTHM. On the other hand, AMSs in the regions of Alibeyköy, Bşakşehir, Esenler, Kağıthane, Sultangazi MTHM, and Şirinevler MTHM have yielded a too high \% variance in $\mathrm{SO}_{2}$ levels. A similar result is also visible for the Asia side. This result is attributable to the distribution of industrial zones in Istanbul. The central government in 
Table 4 Variation in hourly $\mathrm{PM}_{10}$ concentrations before and during PL

\begin{tabular}{|c|c|c|c|c|c|c|c|c|c|c|}
\hline \multicolumn{11}{|l|}{ Europe Side } \\
\hline AMSs & Alibeyköy & Avcilar & \multicolumn{2}{|c|}{ Aksaray } & Bağcılar & \multicolumn{4}{|c|}{ Başakşehir MTHM Beşiktaş } & Esenler \\
\hline $1.03 .2020-09.04 .2020$ & 68.43 & 32.19 & \multicolumn{2}{|c|}{49.30} & 35.22 & 46.09 & \multicolumn{3}{|c|}{33.03} & 37.90 \\
\hline $10.04 .2020-22.05 .2020$ & 42.24 & 32.03 & \multicolumn{2}{|c|}{37.60} & 34.75 & 38.75 & \multicolumn{3}{|c|}{25.40} & 29.41 \\
\hline Variation & -26.19 & -0.16 & \multicolumn{2}{|c|}{-11.70} & -0.47 & -7.35 & \multicolumn{3}{|c|}{-7.62} & -8.49 \\
\hline$\%$ variation & $-38.27 \%$ & $-0.49 \%$ & \multicolumn{2}{|c|}{$-23.74 \%$} & $-1.32 \%$ & $-15.94 \%$ & \multicolumn{3}{|c|}{$-23.08 \%$} & $-22.40 \%$ \\
\hline AMSs & $\begin{array}{l}\text { Esenyurt } \\
\text { MTHM }\end{array}$ & \multicolumn{2}{|c|}{ Kağıthane } & \multicolumn{2}{|c|}{$\begin{array}{l}\text { Mecidiyeköy } \\
\text { MTHM }\end{array}$} & $\begin{array}{l}\text { Sultangazi } \\
\text { MTHM }\end{array}$ & \multicolumn{3}{|c|}{ Silivri MTHM } & $\begin{array}{l}\text { Şirinevler } \\
\text { MTHM }\end{array}$ \\
\hline $1.03 .2020-09.04 .2020$ & 61.94 & \multicolumn{2}{|c|}{74.19} & \multicolumn{2}{|c|}{66.06} & 65.76 & \multicolumn{3}{|c|}{34.62} & 51.31 \\
\hline $10.04 .2020-22.05 .2020$ & 47.22 & \multicolumn{2}{|c|}{50.61} & \multicolumn{2}{|c|}{46.17} & 46.40 & \multicolumn{3}{|c|}{30.54} & 39.93 \\
\hline Variation & -14.72 & \multicolumn{2}{|c|}{-23.58} & \multicolumn{2}{|c|}{-19.89} & -19.36 & \multicolumn{3}{|c|}{-4.08} & -11.38 \\
\hline$\%$ variation & $-23.77 \%$ & \multicolumn{2}{|c|}{$-31.78 \%$} & \multicolumn{2}{|c|}{$-30.11 \%$} & $-29.44 \%$ & \multicolumn{3}{|c|}{$-11.80 \%$} & $-22.17 \%$ \\
\hline \multicolumn{11}{|l|}{ Asia side } \\
\hline AMSs & Kadıköy & \multicolumn{2}{|c|}{ Kandilli MTHM } & \multicolumn{2}{|c|}{ Selimiye } & $\begin{array}{l}\text { Sultanbeyli } \\
\text { MTHM }\end{array}$ & \multicolumn{2}{|c|}{ Ümraniye } & \multicolumn{2}{|c|}{ Usküdar MTHM } \\
\hline $1.03 .2020-09.04 .2020$ & 41.70 & \multicolumn{2}{|l|}{37.53} & \multicolumn{2}{|c|}{40.15} & 42.71 & \multicolumn{2}{|l|}{37.82} & \multicolumn{2}{|l|}{40.05} \\
\hline $10.04 .2020-22.05 .2020$ & 33.35 & 31.26 & & 25 & & 30.87 & 27.19 & & 27.33 & \\
\hline Variation & -8.36 & -6.27 & & & 4.61 & -11.85 & -10.6 & & -12.7 & \\
\hline$\%$ variation & $-20.04 \%$ & $-16.71 \%$ & & & $6.40 \%$ & $-27.73 \%$ & -28.1 & $10 \%$ & -31.7 & $75 \%$ \\
\hline
\end{tabular}

Turkey and Istanbul has taken any decision on restrictions stopping production of the private sector and industry that are sought to be avoided as far as a possible negative influence. Our partial results for the city of Istanbul are compatible with the study of Zhu et al. (2020). In Zhu et al. (2020), a negative correlation is obtained between $\mathrm{SO}_{2}$ level and the number of hourly confirmed Covid-19 cases. Also, in the study of Kerimray et al. (2020) for the city of Almaty, Kazakhstan, an $7 \%$ increase in $\mathrm{SO}_{2}$ concentration has been detected. As in our study, this may be statistically insignificant. However, this result shows that the people used to stay in their houses due to the restrictions and the air temperature was not yet at the desired level for Istanbul due to the burning of the coal used in the houses. As an example of the hourly variation in $\mathrm{SO}_{2}$ concentration for the Aksaray AMS is given in Fig. 5. A noticeable decrease between the two time periods of the years 2019 and 2020 can be observed.

The findings obtained in the $\mathrm{SO}_{2}$ concentration as a result of comparing the Covid-19 outbreak fight dates with the same dates in the previous year are similar to the secondary analysis. As a result, a negative relationship has emerged between the PL dates and the dates when there are few preventive measures for the city of Istanbul. An increase in $\mathrm{SO}_{2}$ levels at different percentages can be easily read from almost all AMSs (Table 6).

\subsection{Carbon monoxide}

$\mathrm{CO}$ concentration is one of the most crucial air quality parameters. $\mathrm{CO}$ is a harmful gas in the atmosphere. It affects the environment and human health heavily. For the city of Istanbul, Turkey, $\mathrm{CO}$ concentration levels have not been obtained as homogenous. As in the trend of $\mathrm{SO}_{2}$ concentration of the Istanbul city, the average values measured at 


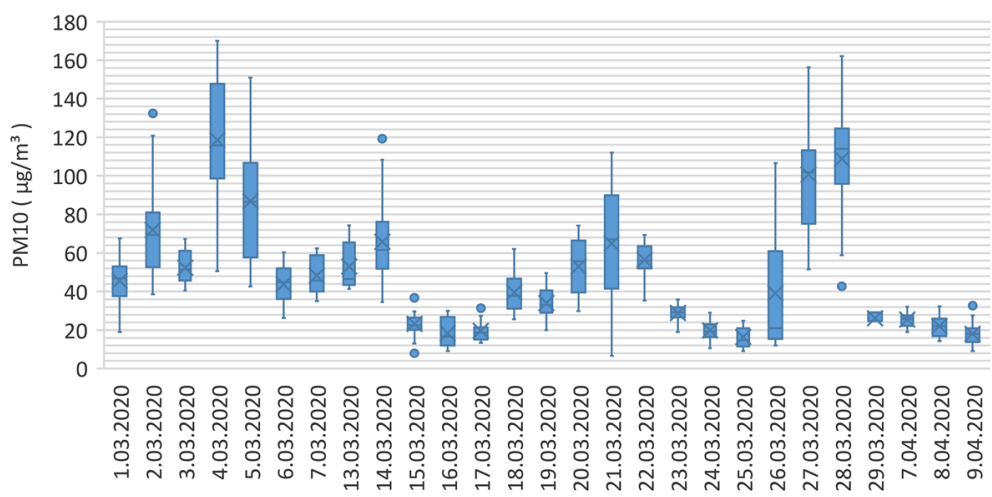

1.03.2020-09.04.2020

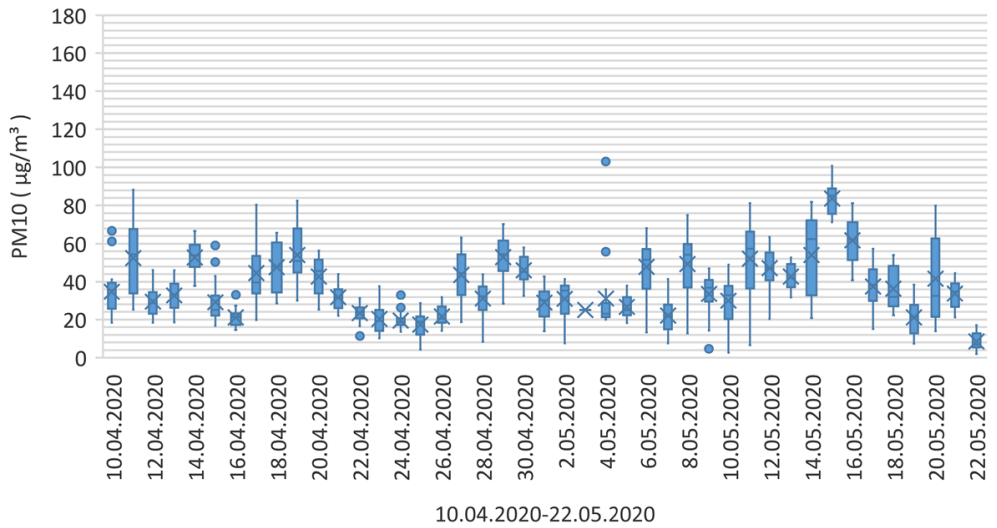

Fig. 4 The variation in $\mathrm{PM}_{10}$ for Aksaray AMS before and during PL

the AMSs mostly have a positive \% variation (Table 7). That means Covid-19 affects air quality negatively in terms of $\mathrm{CO}$ concentration, excluding the regions of Aksaray and Beşiktaş (Fig. 6). These two regions have an improvement in air quality in times of Covid-19 outbreak with a $22.64 \%$ and $38.23 \%$ decrease. Considering the fact that the main causes of higher $\mathrm{CO}$ concentration in the air are due to traffic and household heating, this can only be explained by the fact that people turn to household heating since they frequently prefer not to go outside, excluding a compulsory situation. The CO concentration results obtained for Istanbul contradict the results obtained in many studies in the literature (Xu et al. 2020; Collivignarelli et al. 2020; Nakada et al. 2020; Tobías et al. 2020; Kerimray et al. 2020; Li et al. 2020).

When the situation about CO concentration before and during PL in the Aksaray region in Istanbul is handled, the result is vice versa. The PL decision has significantly decreased the $\mathrm{CO}$ concentration, as given in Table 8 and Fig. 7. This result is completely consistent with the literature. We can infer that the late dates of the PL period (the month of May in 2020) can yield a more consistent result. It is expected to observe a negative effect of Covid-19 on the air quality from the viewpoint of CO concentration 


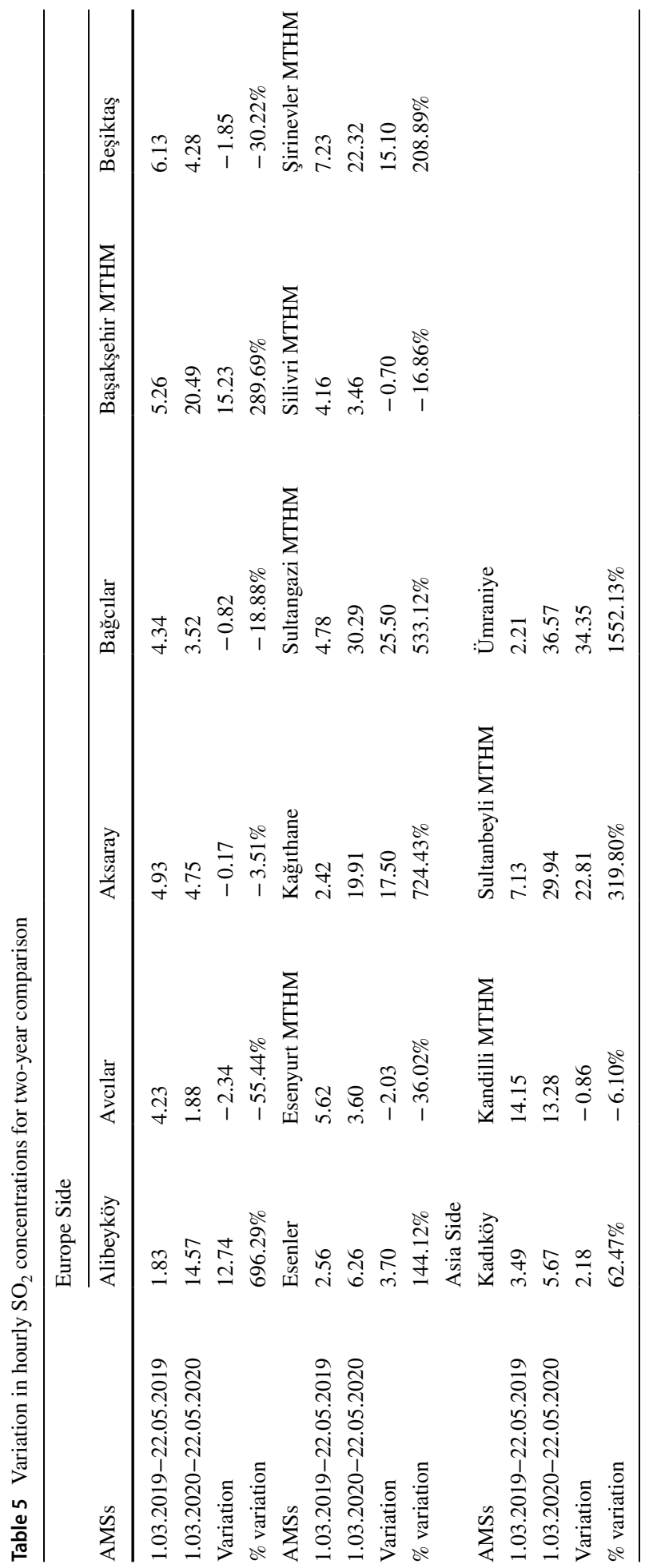




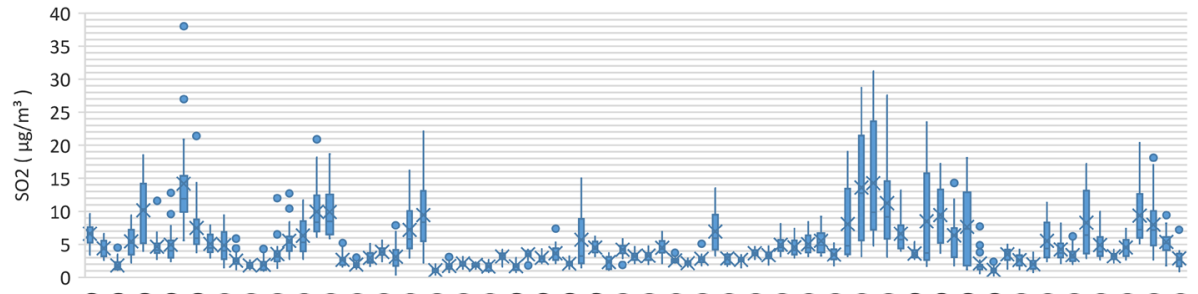

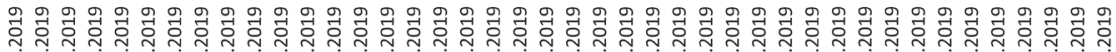

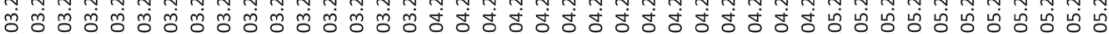
- $\dot{m}$ ம

1.03.2019-07.05.2019

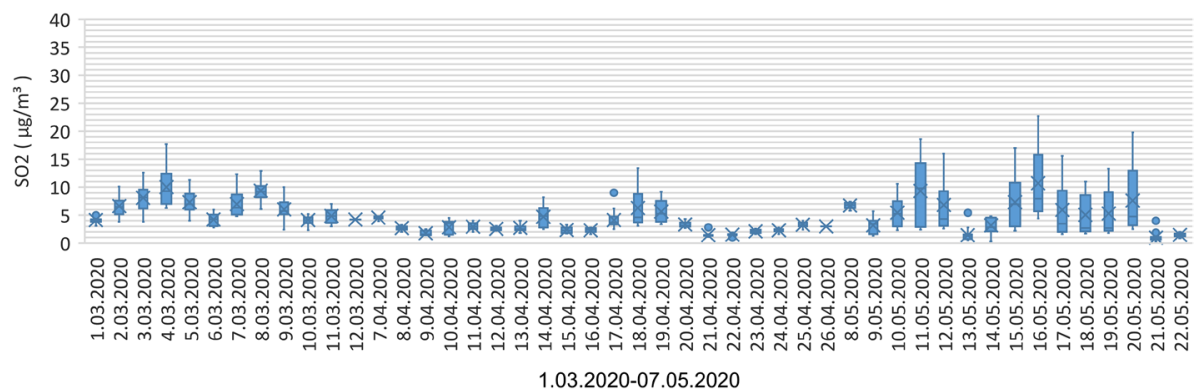

Fig. 5 The variation in $\mathrm{SO}_{2}$ for Aksaray AMS for two-year comparison

in the remaining regions except Aksaray and Beşiktaş with people being more familiar with Covid-19 measures and taking care to comply and warm weathers.

\subsection{Nitrogen dioxide}

Nitrogen dioxide is an air pollutant that is traditionally produced as a result of road traffic and other fossil fuel combustion processes (Collivignarelli et al. 2020). In this paper, we analyzed the concentration of $\mathrm{NO}_{2}$ in AMS in Istanbul. In 2007-2017, the average and standard deviation concentration of $\mathrm{NO}_{2}$ in Istanbul was in fact around $56.57 \pm 10.24{\mu \mathrm{gm}^{3}}^{3}$ (The Ministry of Environment and Urbanisation, 2018). The average concentration, variation, and percentage variation for two periods (1.03.2019-22.05.2019 and 1.03.2020-22.05.2020) are also presented in Table 9. The biggest decrease in $\mathrm{NO}_{2}$ concentrations is realized in Sultanbeyli MTHM AMS with $83.35 \%$. Hourly $\mathrm{NO}_{2}$ concentrations for 4 out of 19 AMSs as Kağıthane, Kadıköy, Selimiye, and Ümraniye are increased.

For example, the variation of $\mathrm{NO}_{2}$ for Aksaray AMS for a two-year comparison is illustrated in Fig. 8. The data are presented as box plots for two year. For $\mathrm{NO}_{2}$, concentrations (average values) in Aksaray AMS are lower $4.67 \%$ for the 1.03.2020-22.05.2020 period by comparing the 1.03.2019-22.05.2019 period.

The variation of hourly $\mathrm{NO}_{2}$ concentrations before PL and during PL is also presented in Table 10. As presented in Table 10, there is a decreasing in hourly $\mathrm{NO}_{2}$ concentrations for all AMSs in Asia side. On the other hand, while $\mathrm{NO}_{2}$ concentrations 


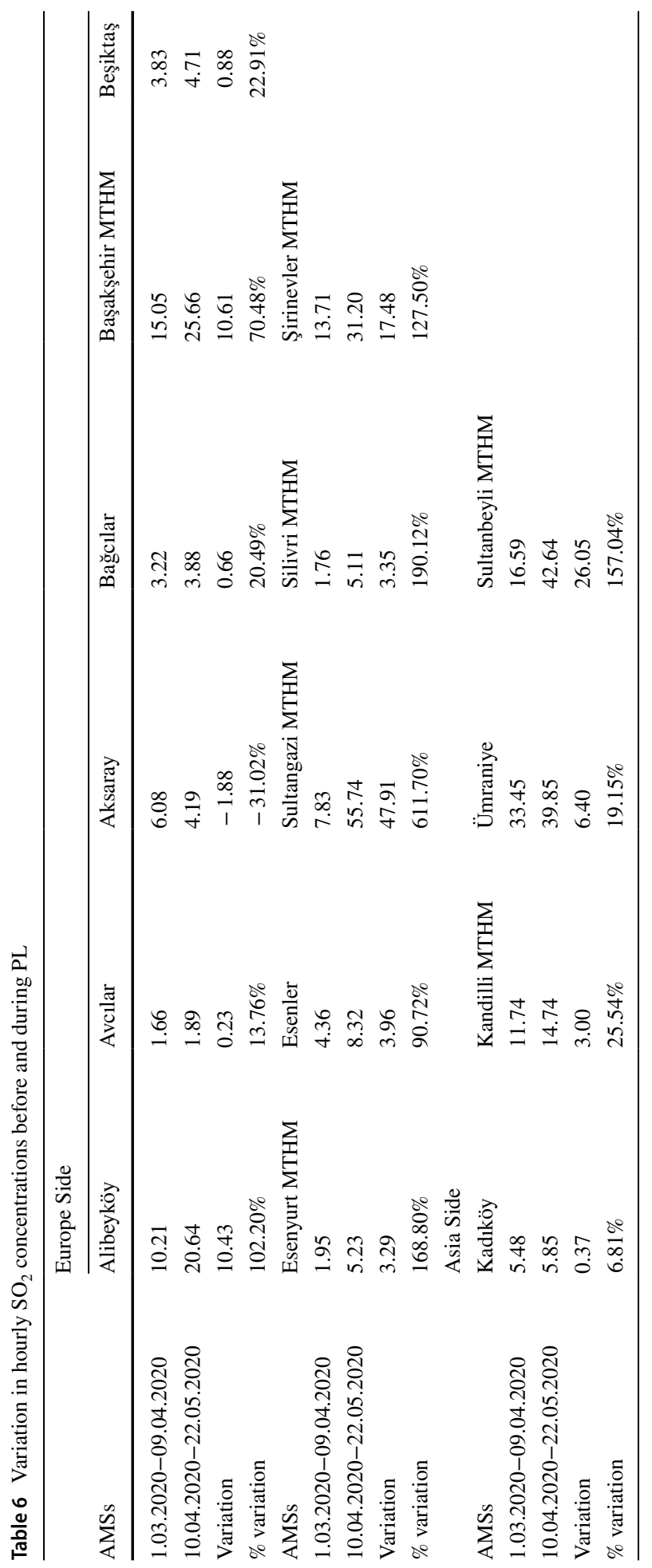


Table 7 Variation in hourly CO concentrations for two-year comparison

\begin{tabular}{llll}
\hline & \multicolumn{2}{l}{ Europe Side } & \\
\cline { 2 - 4 } AMSs & Alibeyköy & Avcılar & Aksaray \\
\hline $1.03 .2019-22.05 .2019$ & 920.61 & 158.21 & 503.45 \\
$1.03 .2020-22.05 .2020$ & 1299.42 & 332.52 & 389.44 \\
Variation & 378.81 & 174.31 & -114.01 \\
\% variation & $41.15 \%$ & $110.17 \%$ & $-22.64 \%$ \\
AMSs & Bağcılar & Başakşehir MTHM & Beşiktaş \\
$1.03 .2019-22.05 .2019$ & 466.16 & 478.99 & 478.75 \\
$1.03 .2020-22.05 .2020$ & 481.58 & 3061.31 & 295.74 \\
Variation & 15.42 & 2582.33 & -183.00 \\
$\%$ variation & $3.31 \%$ & $539.12 \%$ & $-38.23 \%$ \\
AMSs & Kağtthane & Mecidiyeköy MTHM & Şirinevler MTHM \\
$1.03 .2019-22.05 .2019$ & 578.97 & 686.62 & 770.83 \\
$1.03 .2020-22.05 .2020$ & 1776.06 & 1677.13 & 3768.06 \\
Variation & 1197.09 & 990.52 & 2997.23 \\
$\%$ variation & $206.76 \%$ & $144.26 \%$ & $388.83 \%$ \\
AMSs & Asia Side & & \\
$1.03 .2019-22.05 .2019$ & Kandilli MTHM & Selimiye & Üsküdar MTHM \\
$1.03 .2020-22.05 .2020$ & 444.21 & 499.94 & 690.68 \\
Variation & 1671.24 & 1263.09 & 3855.40 \\
\% variation & 1227.03 & 763.14 & 3164.72 \\
\hline & $276.23 \%$ & $152.65 \%$ & $458.20 \%$ \\
\hline
\end{tabular}

are decreased in 11 out of 13 AMSs in Europe side, only 2 out of 13 AMSs as Bağcrlar and Mecidiyeköy MTHM is increased in Table 11.

\subsection{Nitrogen oxide}

In the same manner, the variation of hourly NO concentrations is also analyzed for a twoyear period. There is a reduction of NO concentrations except some AMSs as Kağıthane, Kadıköy, and Ümraniye. While Kağıthane AMS is located in Europe side, the Kadıköy and Ümraniye AMSs are located on the Asia side. These AMSs are specifically located in industrial and transport-dominated areas. There is a significant reduction in Beşiktaş, Bağcrlar and Mediciyeköy AMS in Europe side and Kandilli MTHM AMS in Asia side.

For example, the variation of NO for Aksaray AMS for a two-year comparison is illustrated in Fig. 9. For NO, concentrations (average values) in Aksaray AMS are lower 34.82\% for the 1.03.2020-22.05.2020 period by comparing the 1.03.2019-22.05.2019 period.

In addition to the two-year comparison, an analysis is performed before PL and during PL. There is a significant reduction in hourly NO concentrations except Beşiktaş and Bağcılar AMS in Europe side and Kadıköy AMS in Asia side. While the biggest decreasing is realized on hourly NO concentrations in Aksaray AMS of Europe side, Selimiye AMS also has significant decreasing on hourly NO concentrations for Asia side.

The box plot for the presenting of Aksaray AMS is given in Fig. 10. The 69.04\% reduction is realized during PL. The PL decision has significantly decreased the NO 


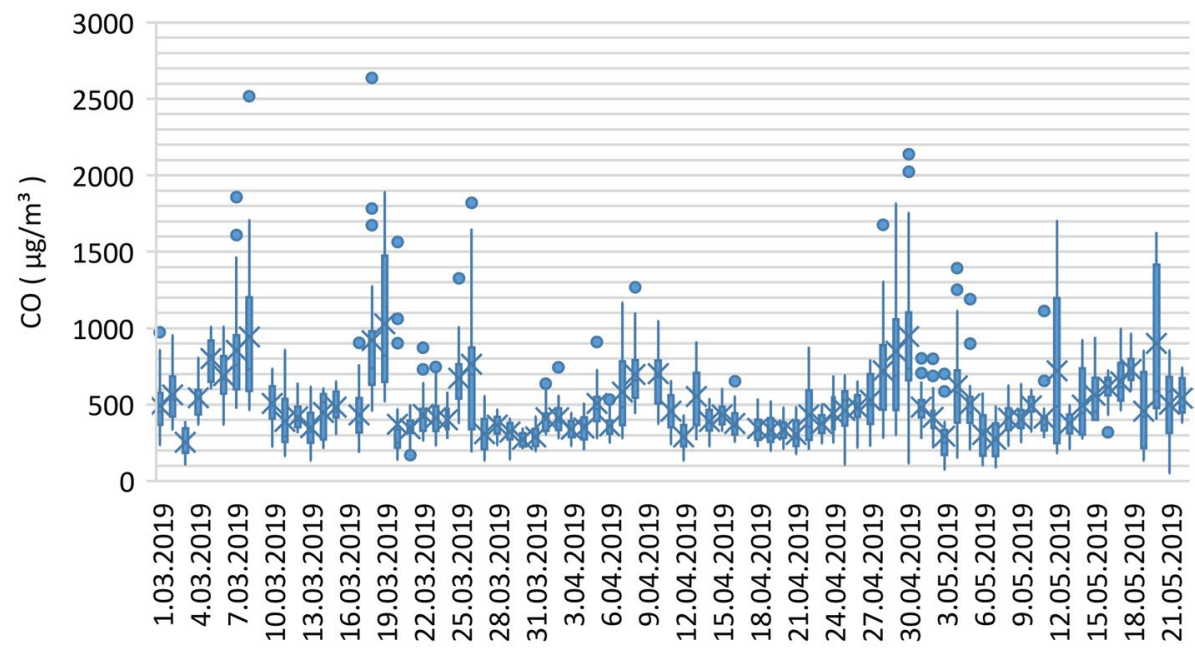

1.03.2019-22.05.2019

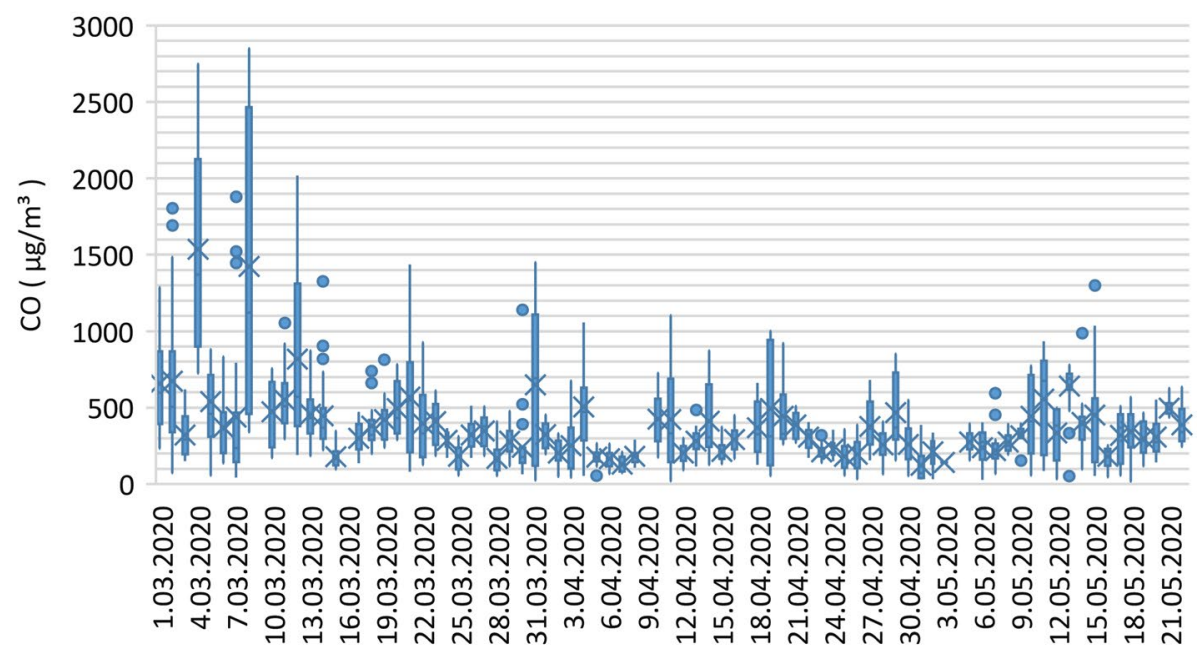

1.03.2020-22.05.2020

Fig. 6 The variation in CO concentration of Aksaray AMS for two-year comparison

concentration, as provided in Table 12 and Fig. 10. This result is entirely consistent with the literature. We can infer that the late dates of the PL period (the month of May in 2020) can yield a more consistent result.

\subsection{Nitrogen oxides}

The main source of the $\mathrm{NO}_{\mathrm{x}}$ is high motor vehicle traffic such as in metropolitan like İstanbul. In this section, we analyzed the variation of hourly $\mathrm{NO}_{\mathrm{x}}$ concentrations for a twoyear comparison. The data of hourly $\mathrm{NO}_{\mathrm{X}}$ concentrations are obtained from 19 AMSs. 
Table 8 Variation in hourly CO concentrations for all AMSs before and during PL

\begin{tabular}{|c|c|c|c|c|c|}
\hline \multirow[b]{2}{*}{ AMSs } & \multicolumn{5}{|l|}{ Europe Side } \\
\hline & Alibeyköy & Avcılar & Aksaray & Bağcılar & Başakşehir MTHM \\
\hline $1.03 .2020-09.04 .2020$ & 1421.98 & 332.77 & 437.86 & 414.60 & 1664.22 \\
\hline $10.04 .2020-22.05 .2020$ & 1138.99 & 294.02 & 338.10 & 547.11 & 4389.60 \\
\hline Variation & -282.98 & -38.75 & -99.76 & 132.51 & 2725.38 \\
\hline$\%$ & $-19.90 \%$ & $-11.65 \%$ & $-22.78 \%$ & $31.96 \%$ & $163.76 \%$ \\
\hline AMSs & Beşiktaş & Esenler & Kağıthane & Mecidiyeköy MTHM & Şirinevler MTHM \\
\hline $1.03 .2020-09.04 .2020$ & 332.31 & 787.01 & 2238.43 & 3273.67 & 2372.79 \\
\hline $10.04 .2020-22.05 .2020$ & 260.24 & 685.39 & 812.02 & 554.74 & 5204.50 \\
\hline Variation & -72.07 & -101.62 & -1426.41 & -2718.93 & 2831.71 \\
\hline$\%$ & $\begin{array}{l}-21.69 \% \\
\text { Asia Side }\end{array}$ & $-12.91 \%$ & $-63.72 \%$ & $-83.05 \%$ & $119.34 \%$ \\
\hline AMSs & Kadıköy & Kandilli MTHM & Selimiye & Üsküdar MTHM & \\
\hline $1.03 .2020-09.04 .2020$ & 83.17 & 1218.01 & 1392.40 & 2184.72 & \\
\hline $10.04 .2020-22.05 .2020$ & 118.02 & 2102.15 & 1090.10 & 5447.08 & \\
\hline Variation & 34.85 & 884.14 & -302.30 & 3262.36 & \\
\hline$\%$ & $41.90 \%$ & $72.59 \%$ & $-21.71 \%$ & $149.33 \%$ & \\
\hline
\end{tabular}

On Europe side, 11 out of 13 AMSs have a significant decreasing in hourly $\mathrm{NO}_{\mathrm{X}}$ concentrations. Only an increasing in hourly $\mathrm{NO}_{\mathrm{X}}$ concentrations is realized on Esenler and Kağıthane AMSs. The variation of the Kağıthane AMS is increased eight times. On the other hand, there is only a 5.16\% increasing in Esenler AMS. In the Asia side, an increasing in hourly $\mathrm{NO}_{\mathrm{X}}$ concentrations is realized on Kadıköy, Selimiye, and Ümraniye AMSs. The variation of the Kadiköy AMS is increased more than four times.

The variation of $\mathrm{NO}_{\mathrm{x}}$ for Aksaray AMS for two-year comparison is illustrated in Fig. 11. For $\mathrm{NO}_{\mathrm{x}}$, concentrations (average values) in Aksaray AMS are lower $22.02 \%$ for the 1.03.2020-22.05.2020 period by comparing the 1.03.2019-22.05.2019 period.

According to this secondary analysis, the $\mathrm{NO}_{\mathrm{x}}$ concentrations from all AMSs have an improvement except Bağcilar and Beşiktaş AMS in Europe side. The average $\mathrm{NO}_{\mathrm{x}}$ values measured from all AMSs between April 10, 2020, and May 22, 2020, were obtained lower than the values measured between March 1, 2020, and April 9, 2020. The \% variation ranges between $16.61 \%$ (Üsküdar MTHM AMS) and 48.70\% (Esenyurt MTHM AMS). The reduction is directly related to the PL decision of the Turkish government. This result is attributable to the travel restrictions in Istanbul and the other 30 megacities of Turkey implemented by the public authority and the reduction in traffic flow, Table 13.

The hourly variation in $\mathrm{NO}_{\mathrm{x}}$ concentration before and during PL measured at Aksaray AMS is shown in Fig. 12. The $41.95 \%$ reduction is realized during PL. The PL decision has significantly decreased the $\mathrm{NO}_{\mathrm{x}}$ concentration, as given in Table 14 and Fig. 12 .

\subsection{Ozone}

$\mathrm{O}_{3}$ is another air pollutant that causes the decrease of NOx in a VOCs-limited environment, a decrease of nitrogen oxide (NO), or a usual increase of insolation and temperatures (Tobías et al. 2020). In 2010-2017, the average and standard deviation concentration of $\mathrm{O}_{3}$ in Istanbul was, in fact around $37.56 \pm 11.65 \mu \mathrm{gm}^{3}$ (The Ministry of Environment and Urbanisation, 2018). In this analysis, we have obtained data for 14 AMSs. The data for 5 

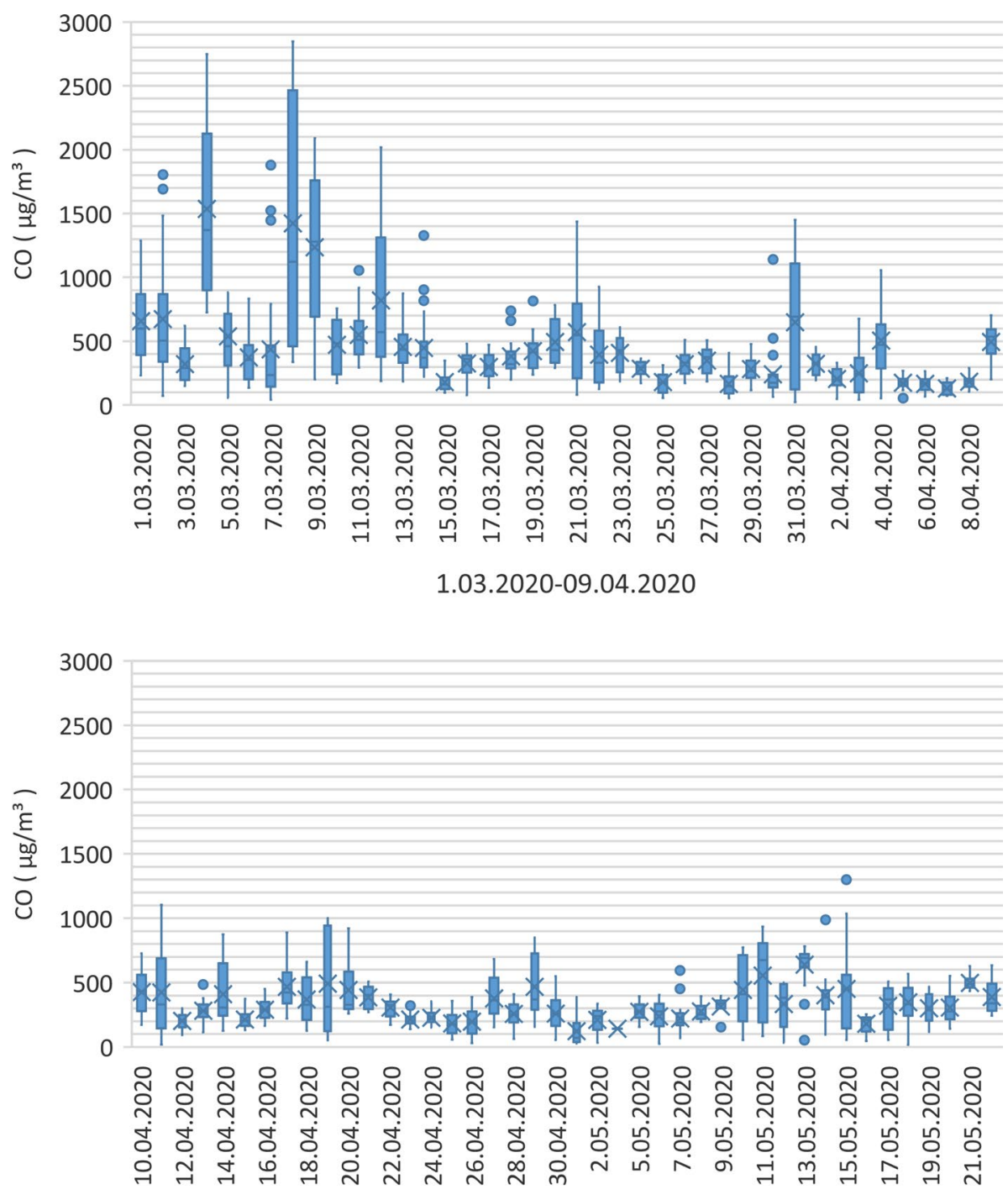

10.04.2020-22.05.2020

Fig. 7 The variation in CO concentration for Aksaray AMS before and after PL

AMSs are not available. The variation of hourly $\mathrm{O}_{3}$ concentrations for a two-year comparison of 15 AMSs is presented in Table 15. There is a significant decreasing for 4 AMSs in Asia side. On the other hand, there is a significant increasing for Alibeyköy AMS with $56.25 \%$.

Figure 10 presents the variation of $\mathrm{O}_{3}$ for Aksaray AMS for a two-year comparison. The concentrations (average values) of NO in Aksaray AMS are lower 13.74\% for the 1.03.2020-22.05.2020 period by comparing the 1.03.2019-22.05.2019 period, Fig. 13. 


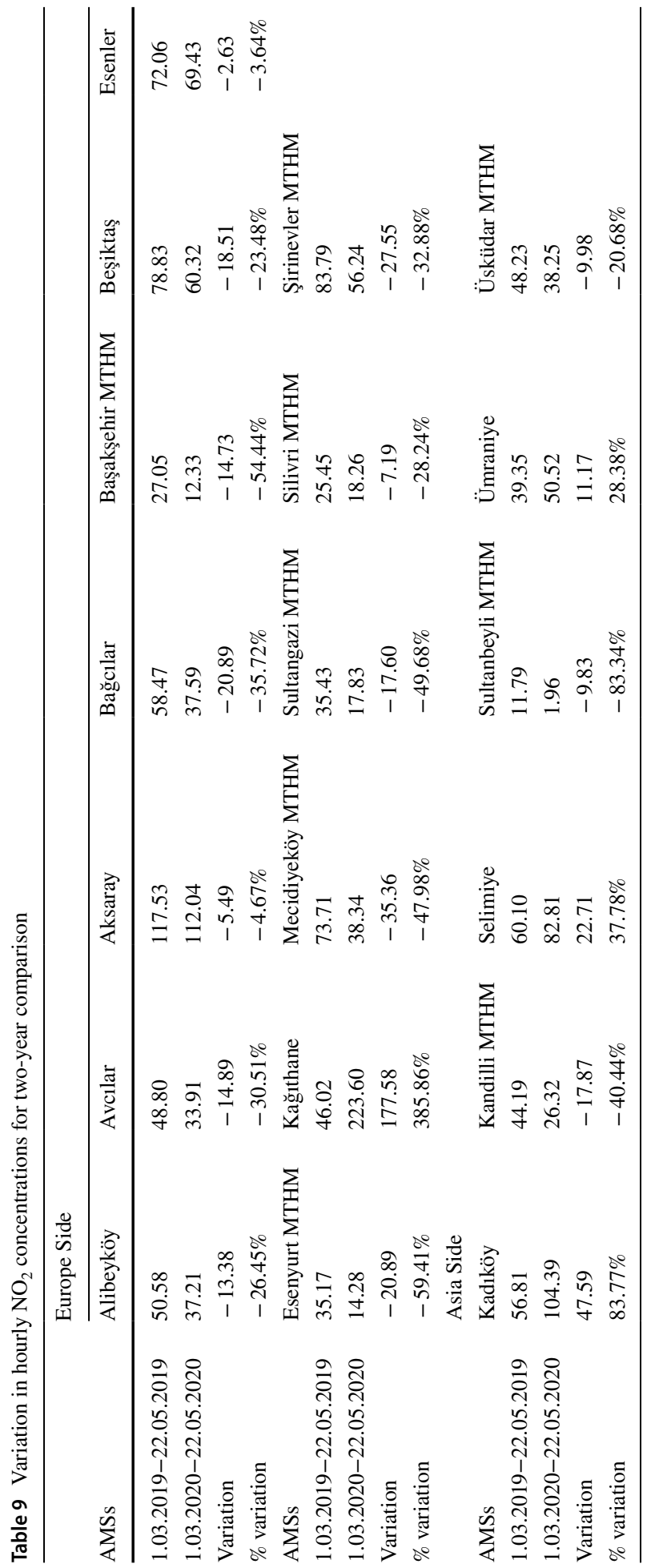




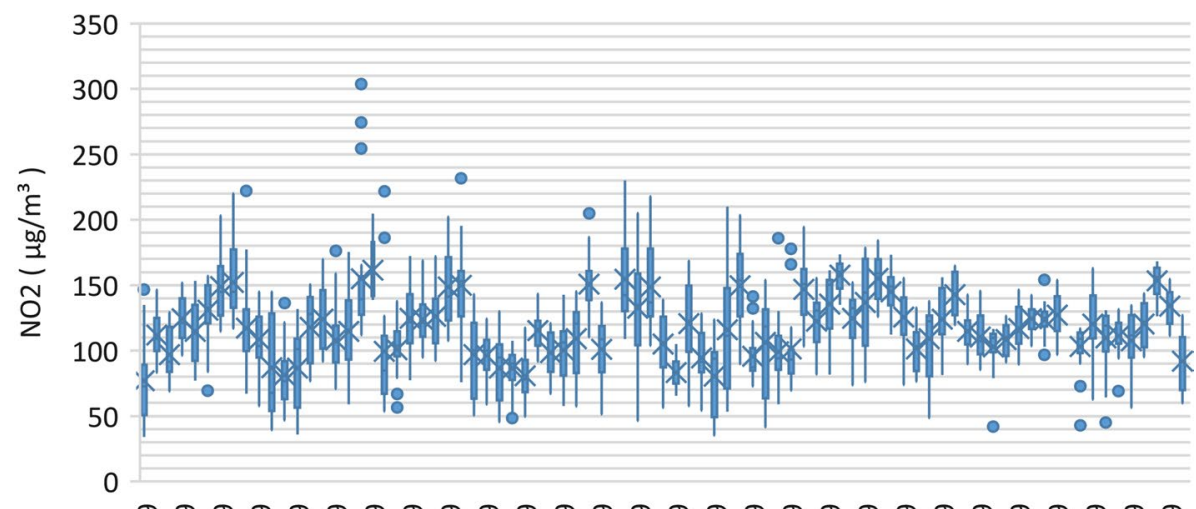

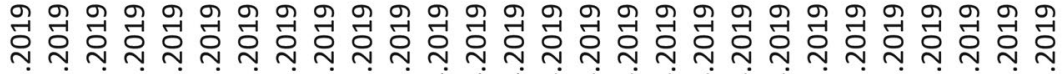

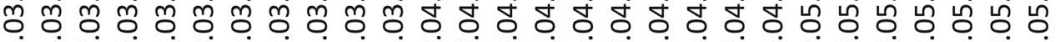

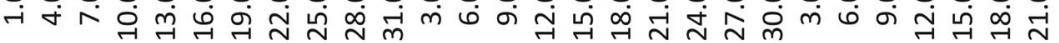

1.03.2019-22.05.2019

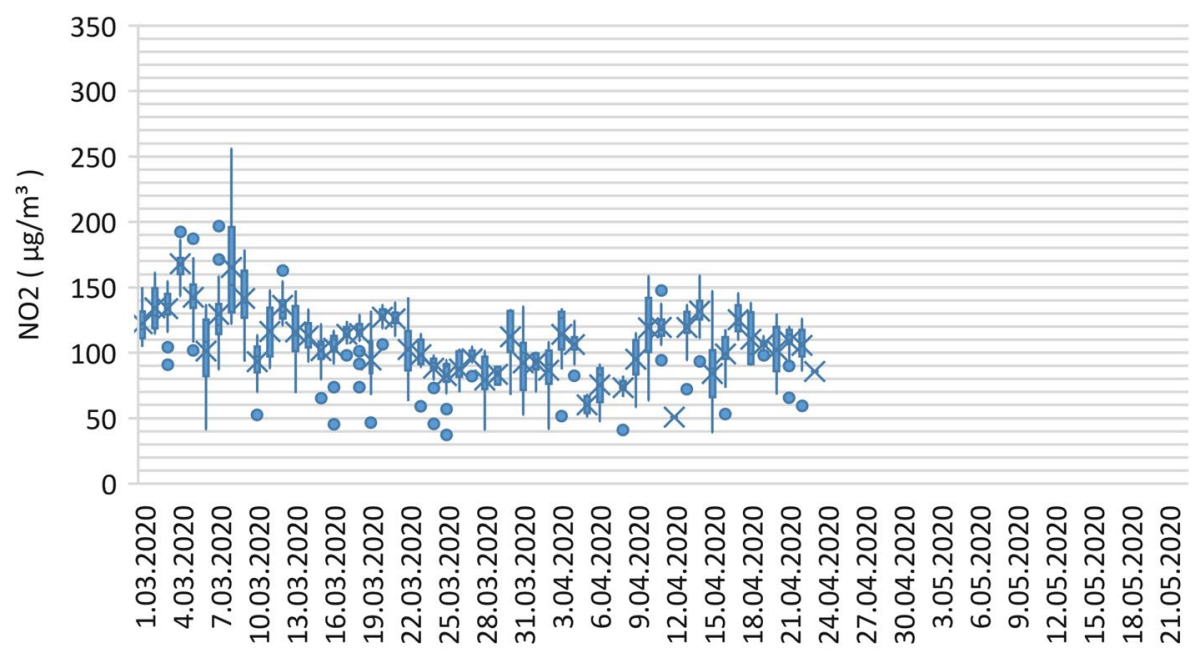

1.03.2020-22.05.2020

Fig. 8 The variation in $\mathrm{NO}_{2}$ of Aksaray AMS for two-year comparison

According to this secondary analysis, the $\mathrm{O}_{3}$ concentrations from 7 out of 9 AMSs have an improvement except for Bağcılar and Kağıthane AMS in Europe side. In Asia side, while there is a significant increasing in the $\mathrm{O}_{3}$ concentrations on Selimiye (41.13\%) and Sultanbeyli (22.41\%) AMSs, a significant decreasing is also realized in Ümraniye AMS (28.79\%). 


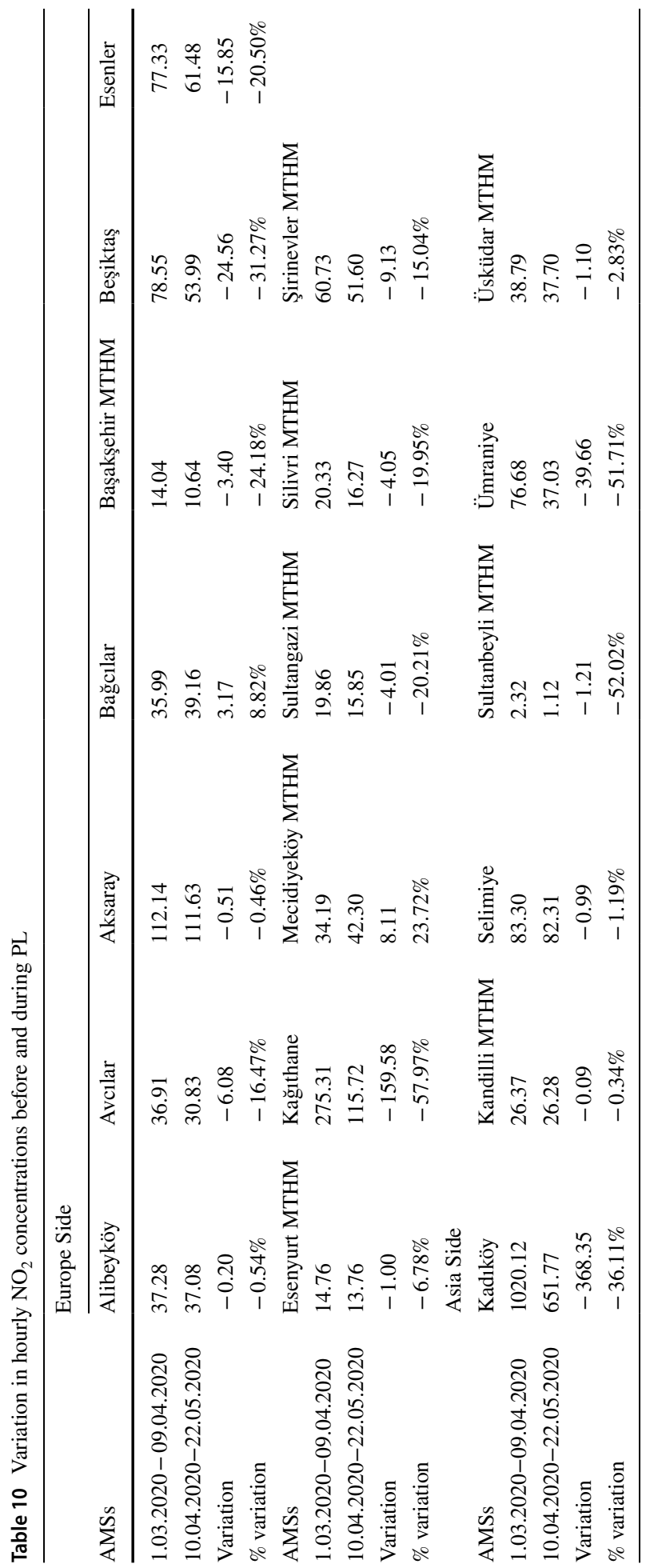




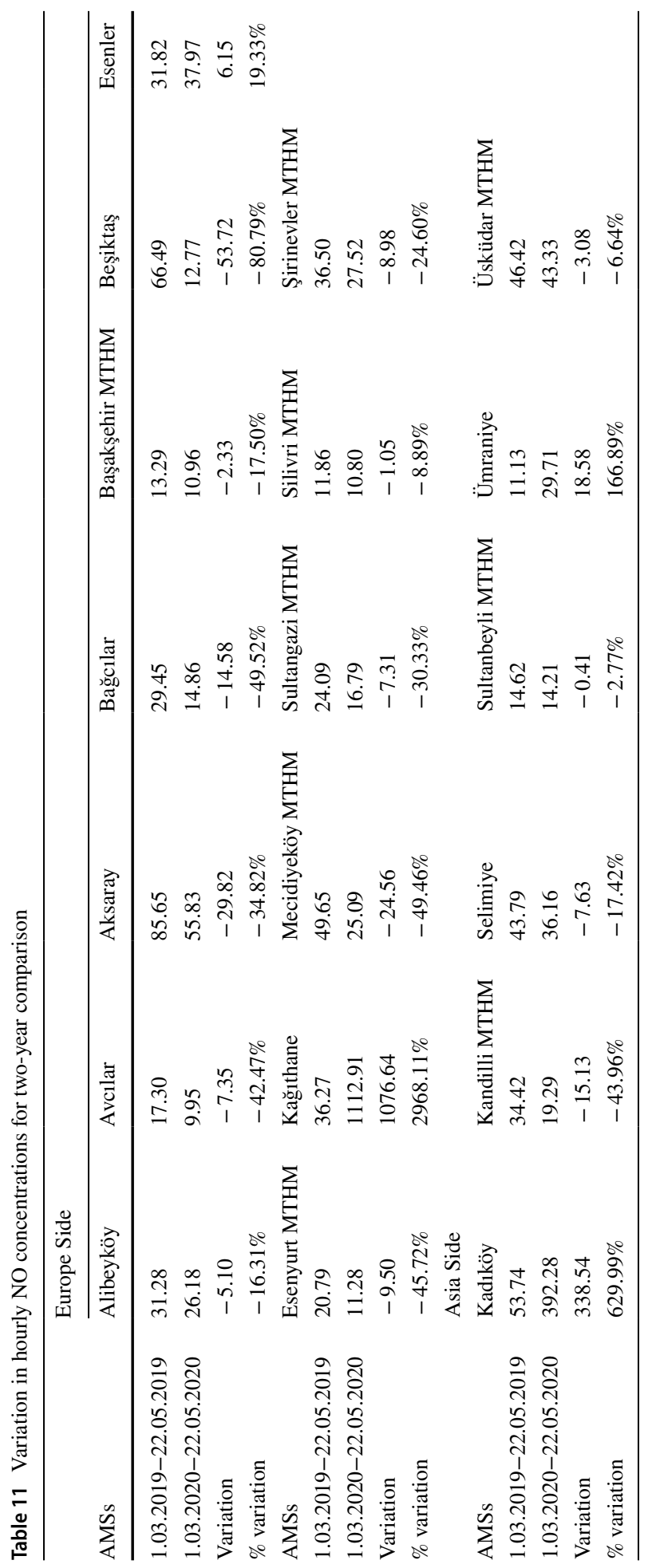




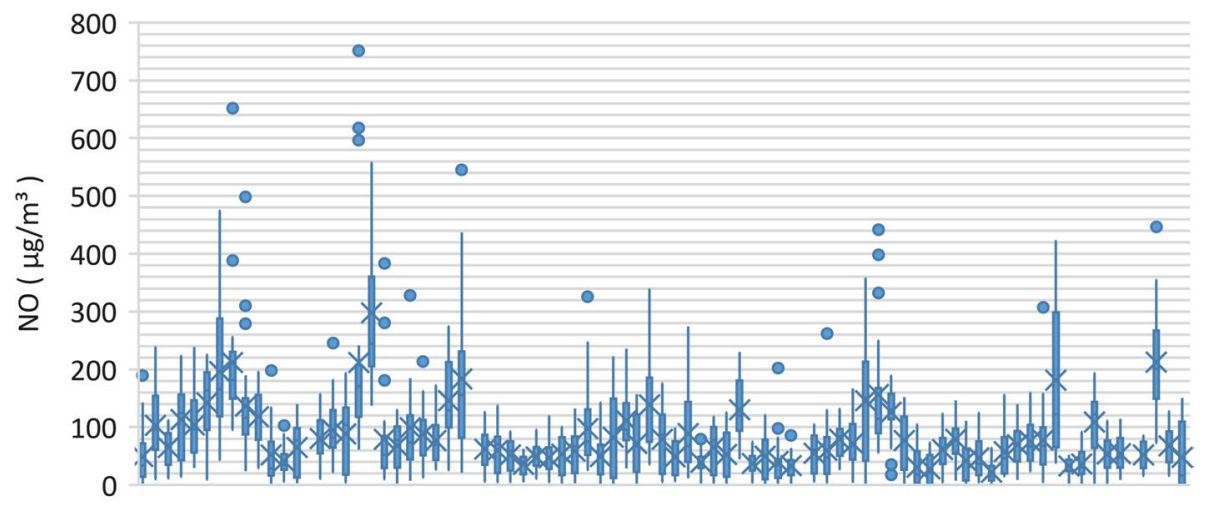

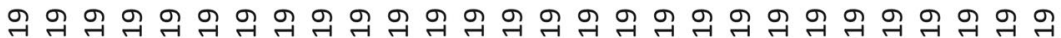

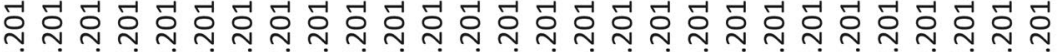

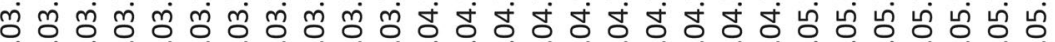
궁ㄱ

1.03.2019-22.05.2019

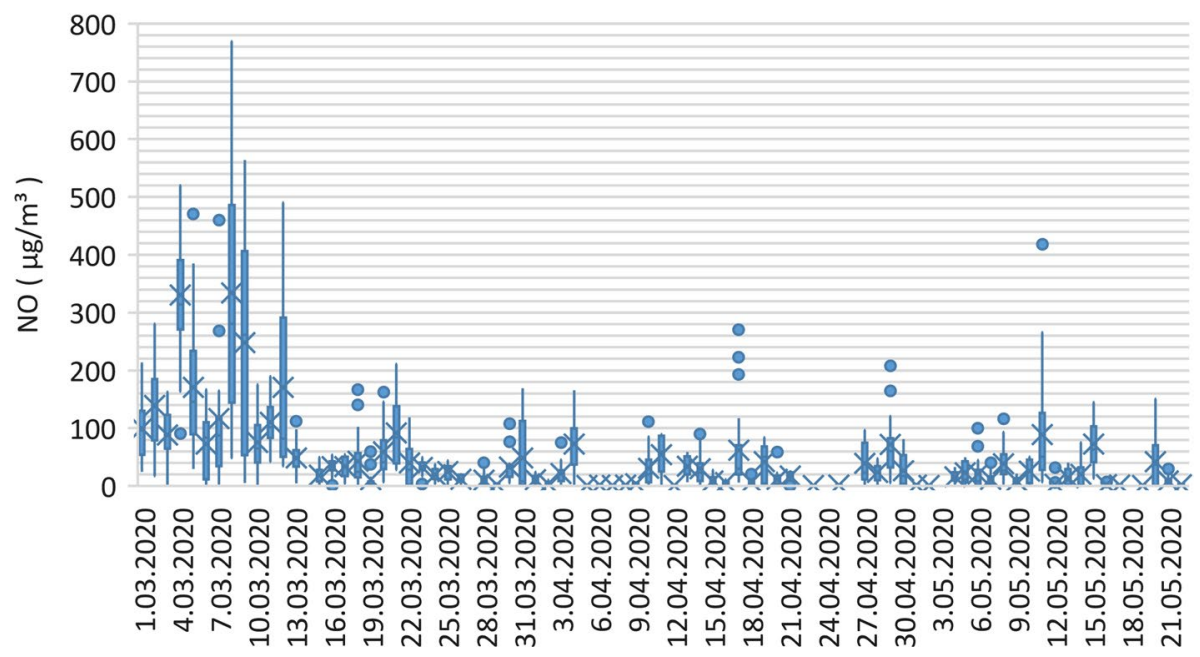

1.03.2020-22.05.2020

Fig. 9 The variation in NO of Aksaray AMS for two-year comparison

The hourly variation in $\mathrm{O}_{3}$ concentration before and during PL measured at Aksaray AMS is shown in Fig. 14. The 56.22\% increasing is realized during PL. The PL decision has significantly increased the $\mathrm{O}_{3}$ concentration, as given in Table 16 and Fig. 14 . 


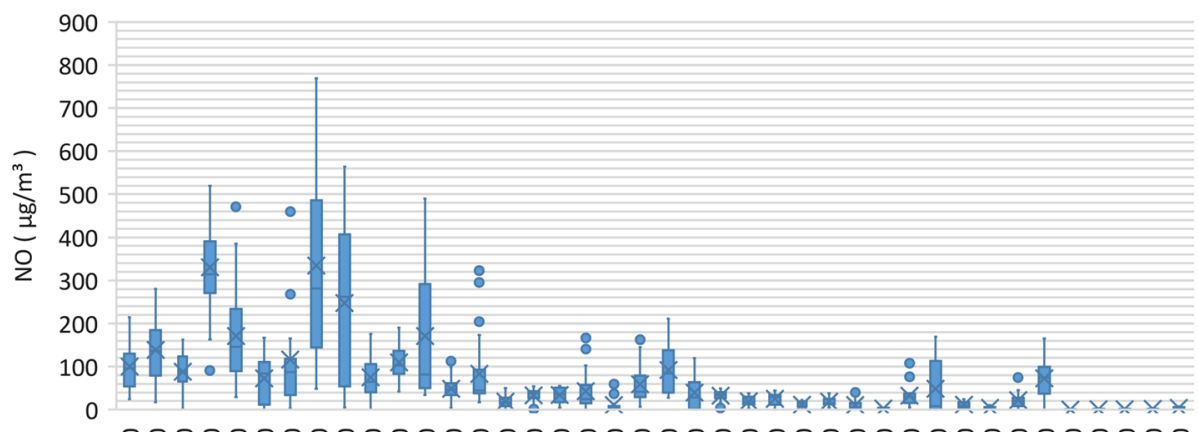

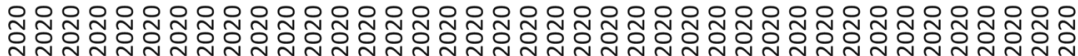

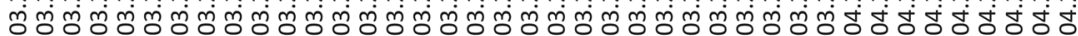
-

\subsubsection{0-09.04.2020}

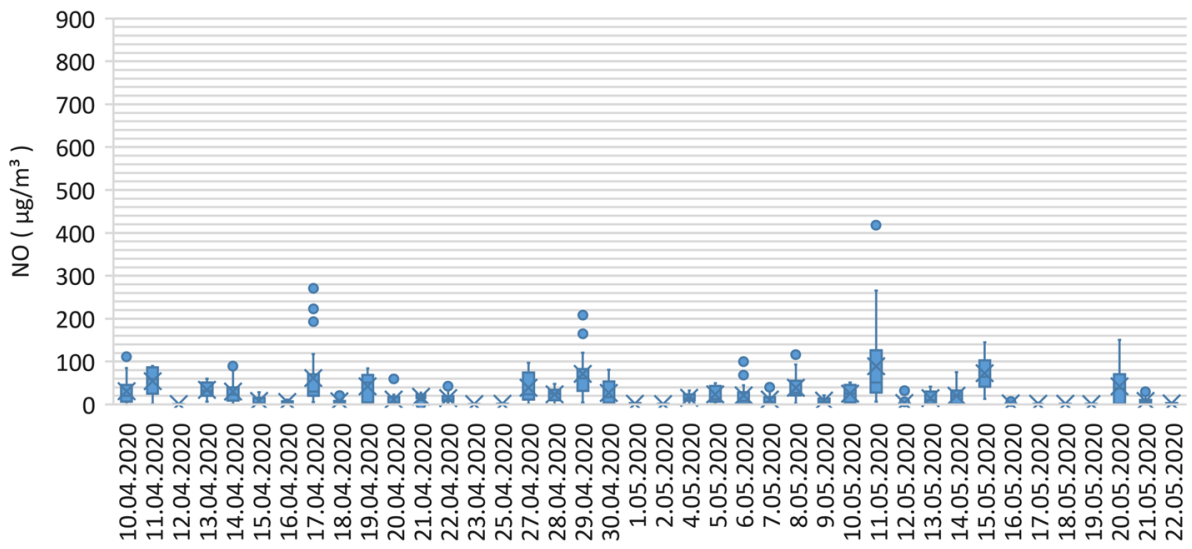

10.04.2020-22.05.2020

Fig. 10 The variation in NO of Aksaray AMS before and during PL

\section{Conclusion}

In this paper, the impact of the COVID-19 pandemic on the air quality of Istanbul city is compared and discussed considering the particulate matter $\left(\mathrm{PM}_{10}\right)$, sulfur dioxide $\left(\mathrm{SO}_{2}\right)$, carbon monoxide (CO), sulfur dioxide $\left(\mathrm{NO}_{2}\right)$, sulfur oxide (NO), sulfur oxides ( $\left.\mathrm{NOx}\right)$, and ozone (O3) concentrations. The concentrations of $\mathrm{PM}_{10}, \mathrm{SO}_{2}, \mathrm{CO}, \mathrm{NO}_{2}, \mathrm{NO}, \mathrm{NO}_{\mathrm{x}}$, and $\mathrm{O}_{3}$ were obtained at 1-h intervals. The data are obtained from 19 AMSs of different districts of Istanbul. The change of concentrations was handled by comparisons in two different time periods. The first analysis compares the values of March 1, 2020-May 22, 2020, and the same dates from the year 2019. In this first analysis, 1992 concentrations for each parameter, and each AMS are obtained. The second analysis includes the comparison of the values between March 1, 2020-April 9, 2020, and April 10, 2020-May 22, 2020. The dates of this second analysis refer to before and after the partial lockdown for Istanbul. While 960 concentrations for each parameter and each AMS for before lockdown are obtained, 1032 concentrations for each parameter and each AMS for during lockdown are obtained. 


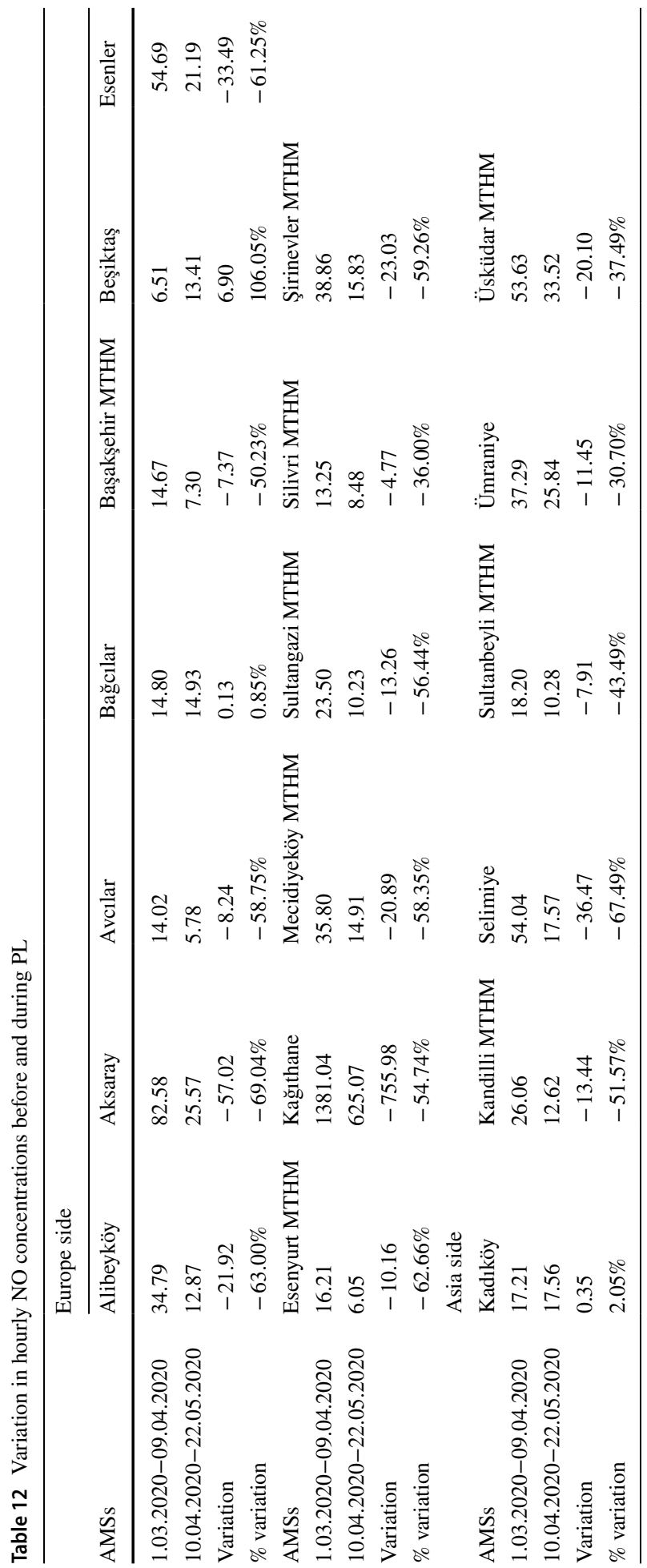




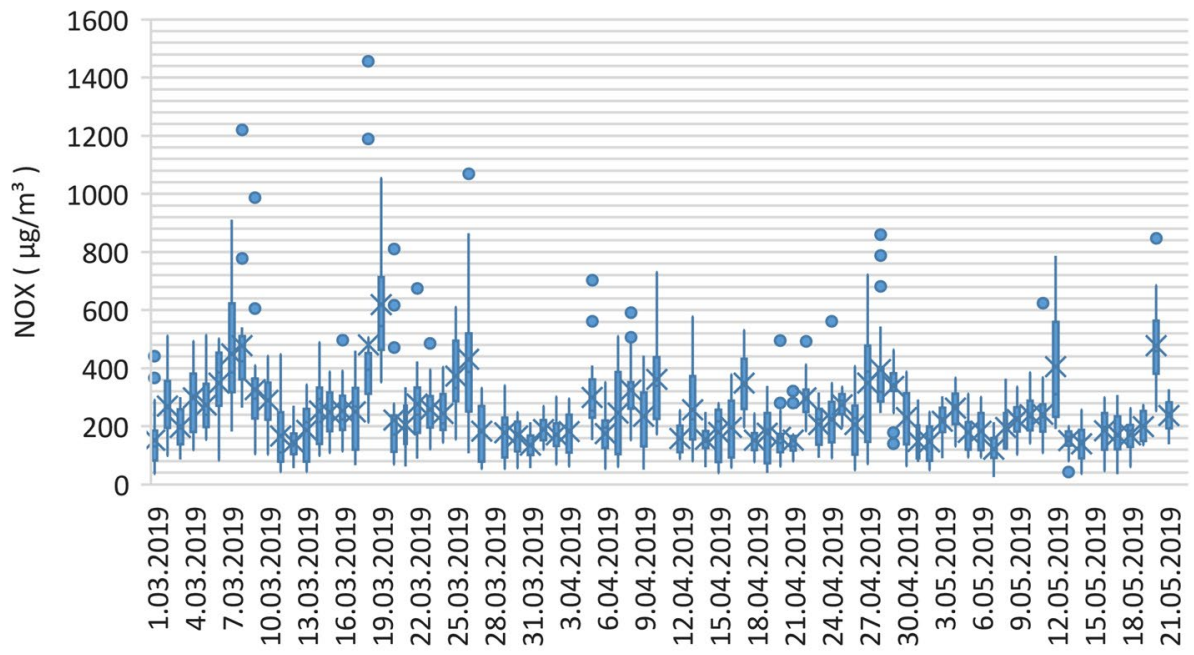

1.03.2019-22.05.2019

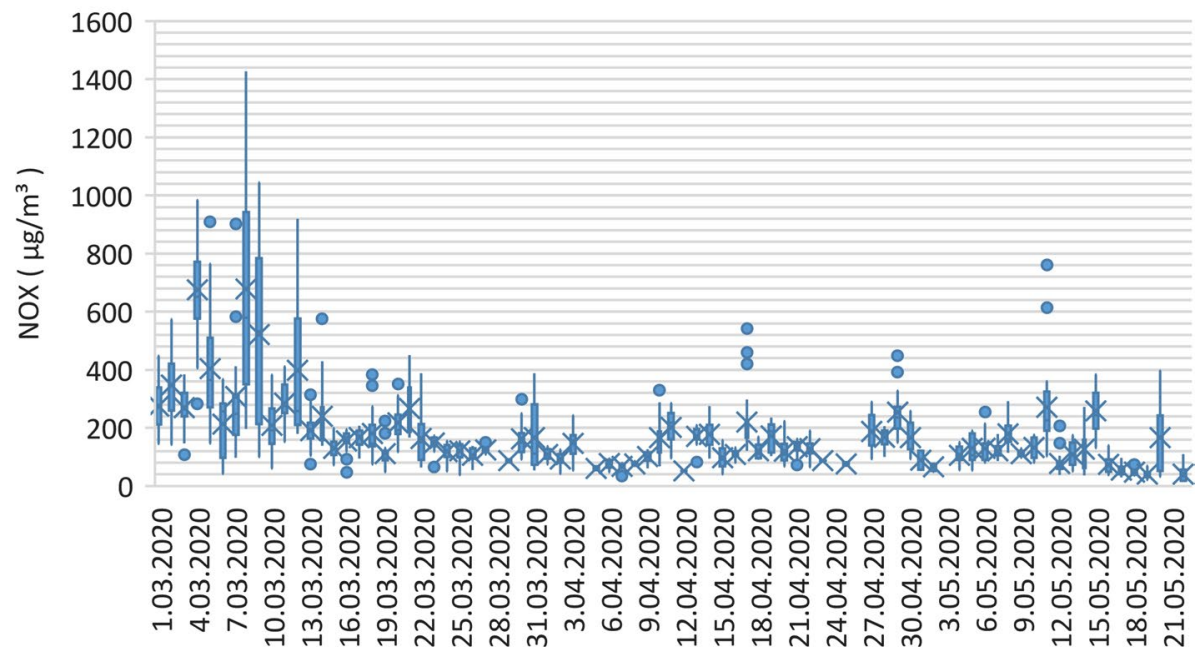

\subsubsection{0-22.05.2020}

Fig. 11 The variation in $\mathrm{NO}_{\mathrm{x}}$ of Aksaray AMS for two-year comparison

The variation in the mean concentration between both periods and their relative change are calculated and compared. While the reduction of $\mathrm{PM}_{10}$ of concentration is 19 AMSs ranged between $1.19 \%$ and $29.19 \%$ for two-year period, the reduction of $\mathrm{PM}_{10}$ concentration of 19 AMSs is ranged between $1.32 \%$ and $38.27 \%$ before PL and during PL. The reduction of CO concentration of 8 AMSs is ranged between $11.65 \%$ and $83.05 \%$ before PL and during PL. In 17 AMSs, the concentration of $\mathrm{NO}_{2}, \mathrm{NO}$, and $\mathrm{NO}_{\mathrm{x}}$ is significantly reduced before PL and during PL. The variation of $\mathrm{O}_{3}$ depends on the AMSs. While the maximum reduction $\mathrm{O}_{3}$ of concentration is $78.71 \%$, the maximum increasing $\mathrm{O}_{3}$ concentration is $61.67 \%$. 


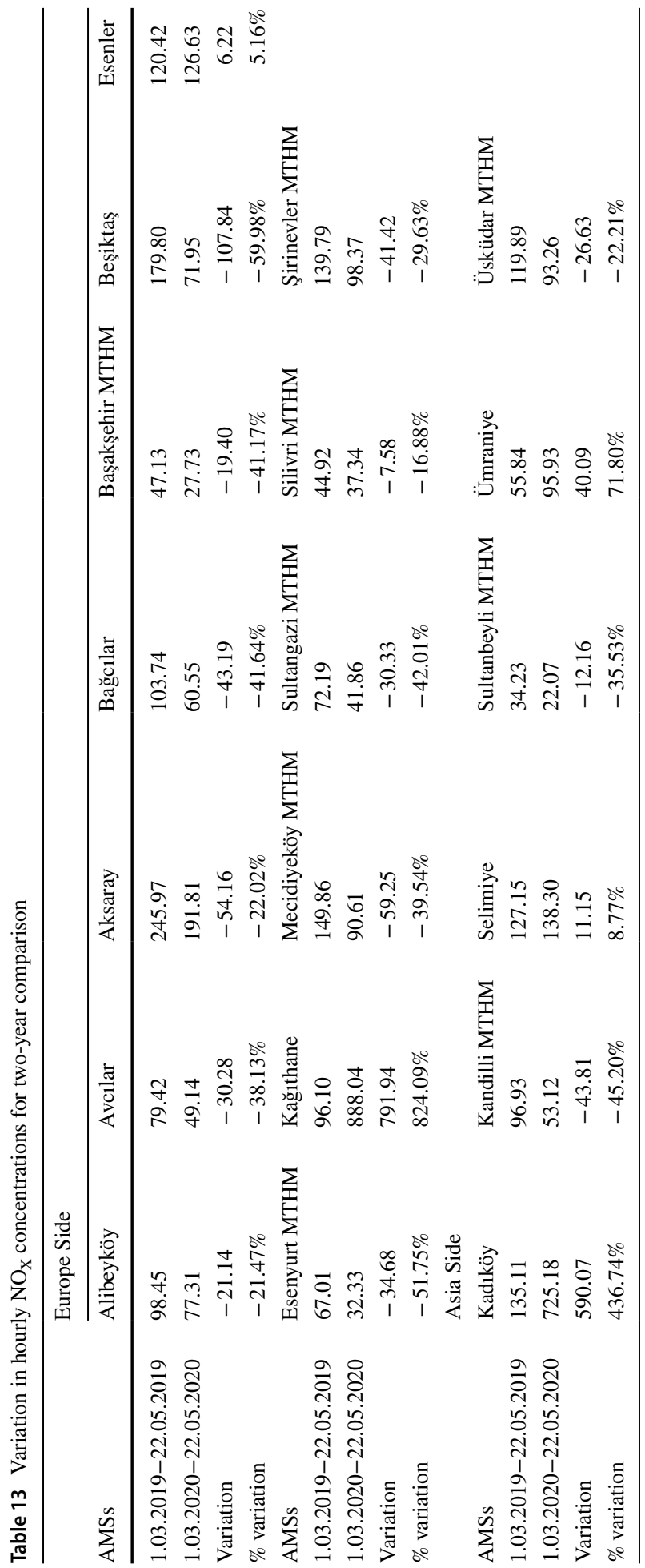




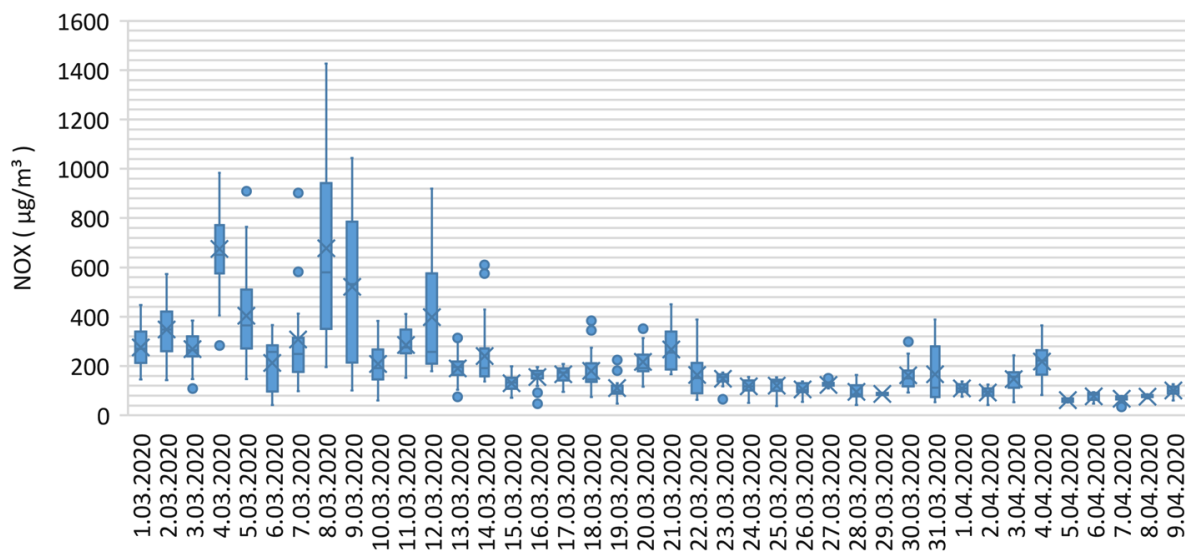

1.03.2020-09.04.2020

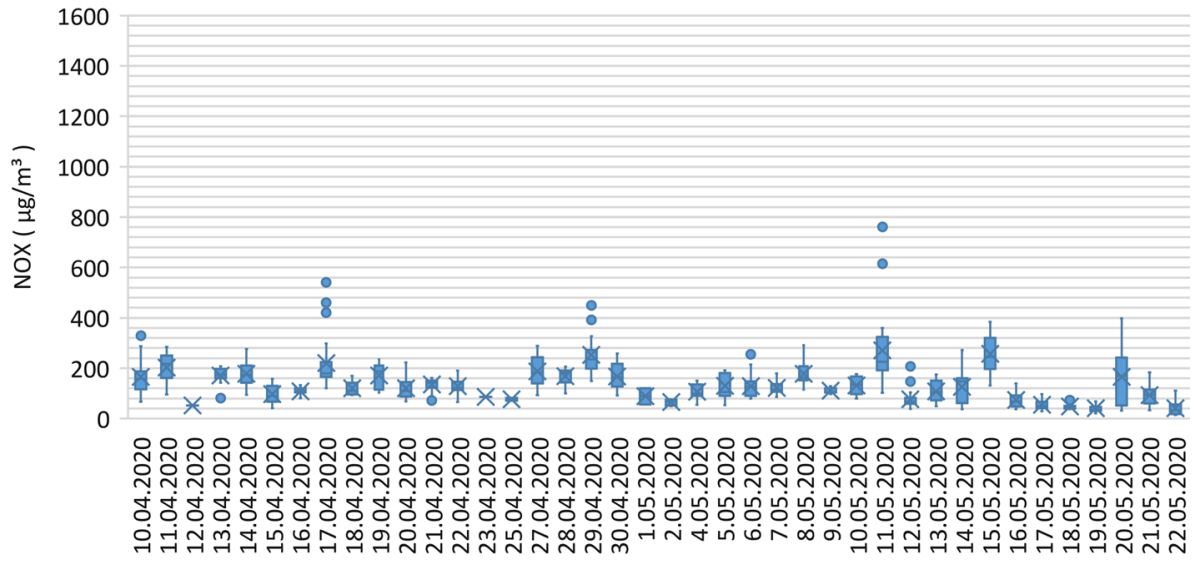

10.04.2020-22.05.2020

Fig. 12 The variation in $\mathrm{NO}_{\mathrm{X}}$ of Aksaray AMS before and after PL

This study comprehensively discussed the impact of the COVID-19 on the environment of Istanbul, the metropolitan city of Turkey. The main implications from the study are as follows:

The COVID-19 pandemic improved the air quality of Istanbul in the short term and made a significant contribution to reducing carbon emissions. Also, considering the time period, energy consumption dropped during the COVID-19 outbreak. It has significantly reduced the emissions of gases such as $\mathrm{CO}$. However, observed data show that this beneficial effect only partially occurred during PL. Therefore, with the removal of PL decisions in the future, people and goods will begin to flow mostly, making it possible for energy use and gas emissions to reach the level before the epidemic.

For Istanbul, COVID-19 significantly reduced NO2, NO, and NOx concentrations in the atmosphere. The reduced traffic flow in PL times has significantly improved air quality throughout the province. This phenomenon may indicate a close relationship between the economy and environmental pollution. The decrease in economic activity and traffic bans 


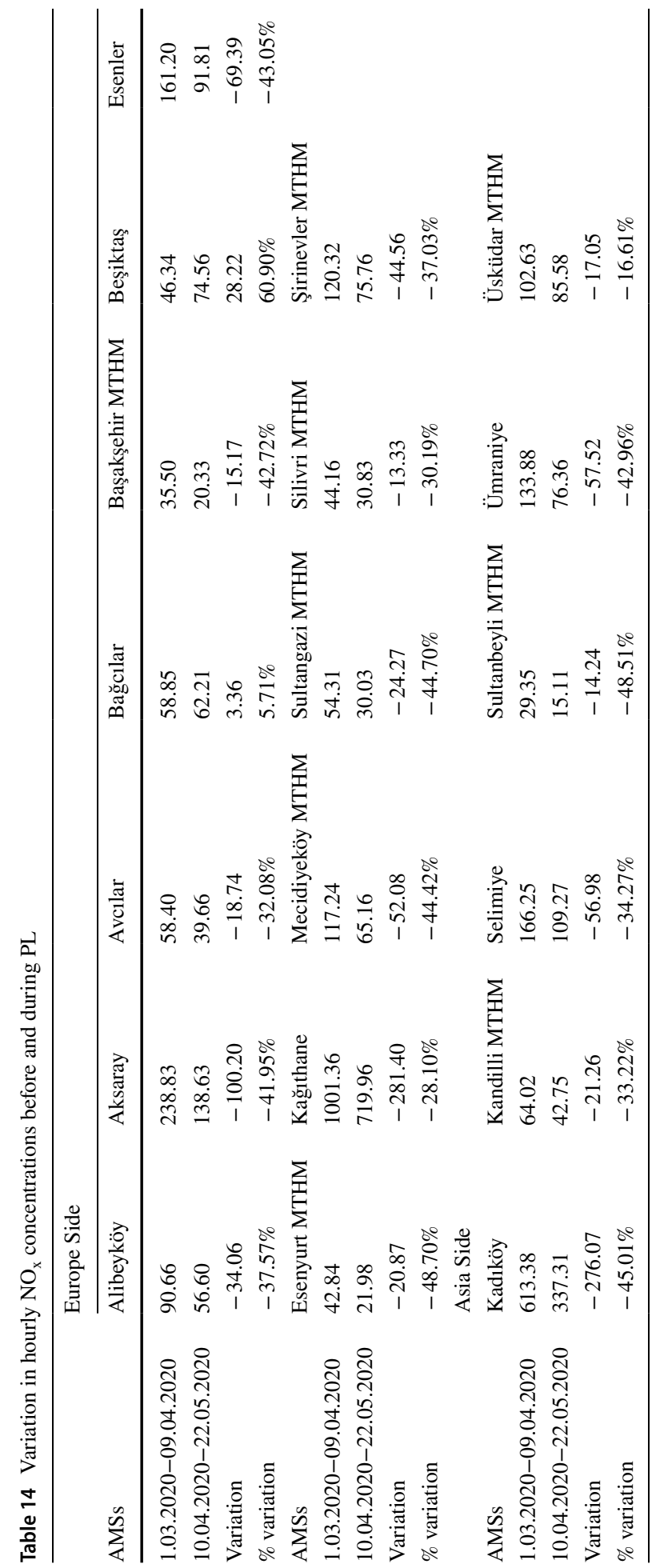


Table 15 Variation in hourly $\mathrm{O}_{3}$ concentrations for two-year comparison

\begin{tabular}{|c|c|c|c|c|c|}
\hline \multirow[b]{2}{*}{ AMSs } & \multicolumn{5}{|l|}{ Europe Side } \\
\hline & Alibeyköy & Aksaray & Bağcılar & Başakşehir MTHM & Beşiktaş \\
\hline $1.03 .2019-22.05 .2019$ & 19.50 & 32.49 & 40.42 & 63.81 & 25.64 \\
\hline $1.03 .2020-22.05 .2020$ & 30.47 & 28.02 & 44.35 & 74.23 & 25.63 \\
\hline Variation & 10.97 & -4.46 & 3.93 & 10.42 & -0.01 \\
\hline$\%$ variation & $56.25 \%$ & $-13.74 \%$ & $9.71 \%$ & $16.33 \%$ & $-0.04 \%$ \\
\hline AMSs & Esenyurt MTHM & Kağıthane & Sultangazi MTHM & Silivri MTHM & \\
\hline 1.03.2019-22.05.2019 & 14.22 & 42.91 & 51.92 & 74.32 & \\
\hline $1.03 .2020-22.05 .2020$ & 14.27 & 8.86 & 33.03 & 72.19 & \\
\hline Variation & 0.04 & -34.05 & -18.90 & -2.13 & \\
\hline$\%$ variation & $\begin{array}{l}0.31 \% \\
\text { Asia Side }\end{array}$ & $-79.36 \%$ & $-36.39 \%$ & $-2.87 \%$ & \\
\hline AMSs & Kadıköy & Selimiye & Sultanbeyli MTHM & Ümraniye & \\
\hline 1.03.2019-22.05.2019 & 23.53 & 38.20 & 66.47 & 41.00 & \\
\hline $1.03 .2020-22.05 .2020$ & 17.40 & 20.98 & 65.02 & 14.60 & \\
\hline Variation & -6.14 & -17.22 & -1.46 & -26.40 & \\
\hline$\%$ variation & $-26.08 \%$ & $-45.07 \%$ & $-2.19 \%$ & $-64.39 \%$ & \\
\hline
\end{tabular}

directly affected changes in energy consumption of Istanbul metropolis and effectively reduced environmental pollution.

This study contributed to research on the impact of some strict measures taken by decision-makers in the event of a global disaster such as the COVID-19 pandemic on air quality and environmental pollution. This type of research has been conducted in metropolitan cities in many countries in the world. However, such research has not yet been conducted for Turkey. In this context, a reference study with the Istanbul case has been added to the studies on the evaluation of the impact of COVID-19 on the environment. This study has also taken its place in the literature as a study contributing to global studies under the disaster situation-economy-environment perspective.

For future studies, by adding meteorological data to such a study, a holistic evaluation can be made with the effect of climatic variables. Moreover, it should be noted that factors of jam and industrial activities should be taken into consideration for further studies. 


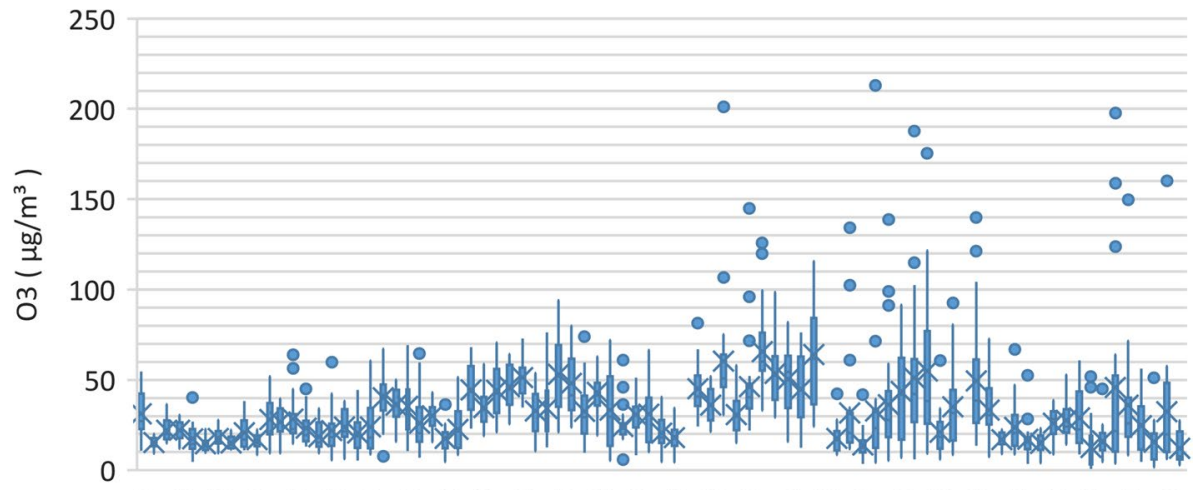

궁 न

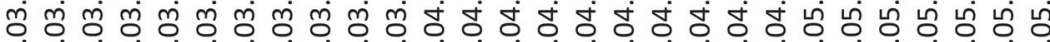

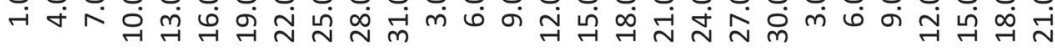

1.03.2019-22.05.2019

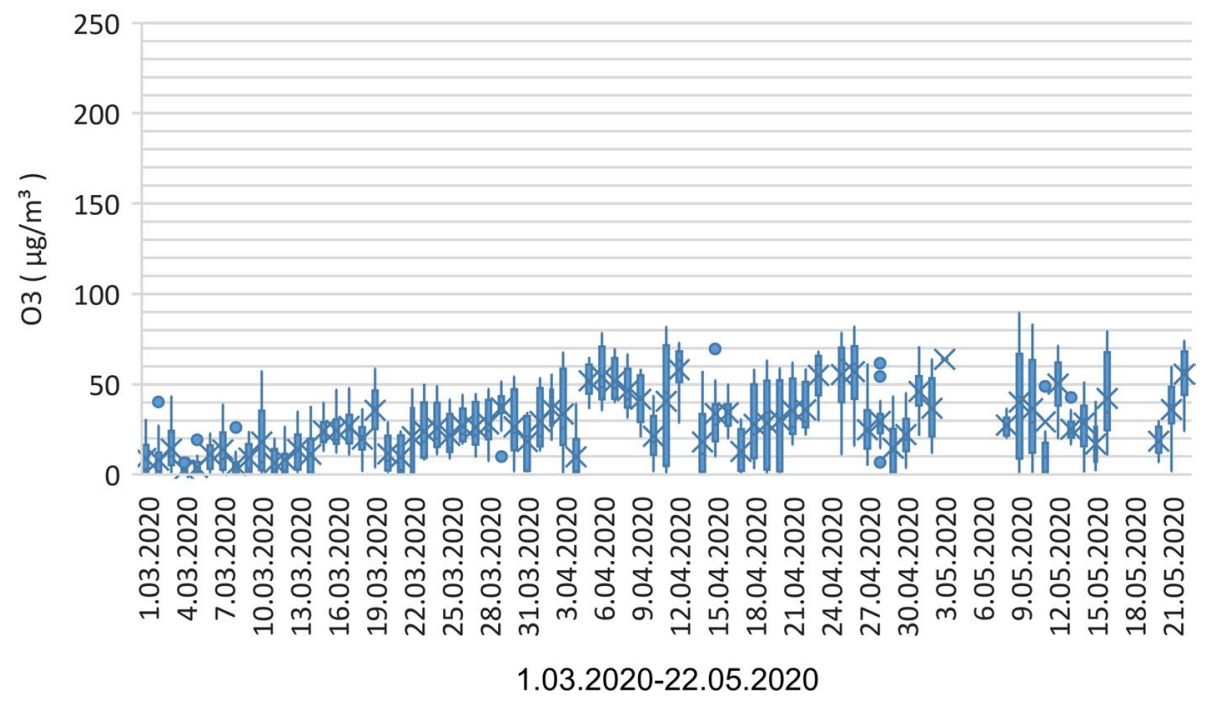

Fig. 13 The variation in $\mathrm{O}_{3}$ for Aksaray AMS for two-year comparison 


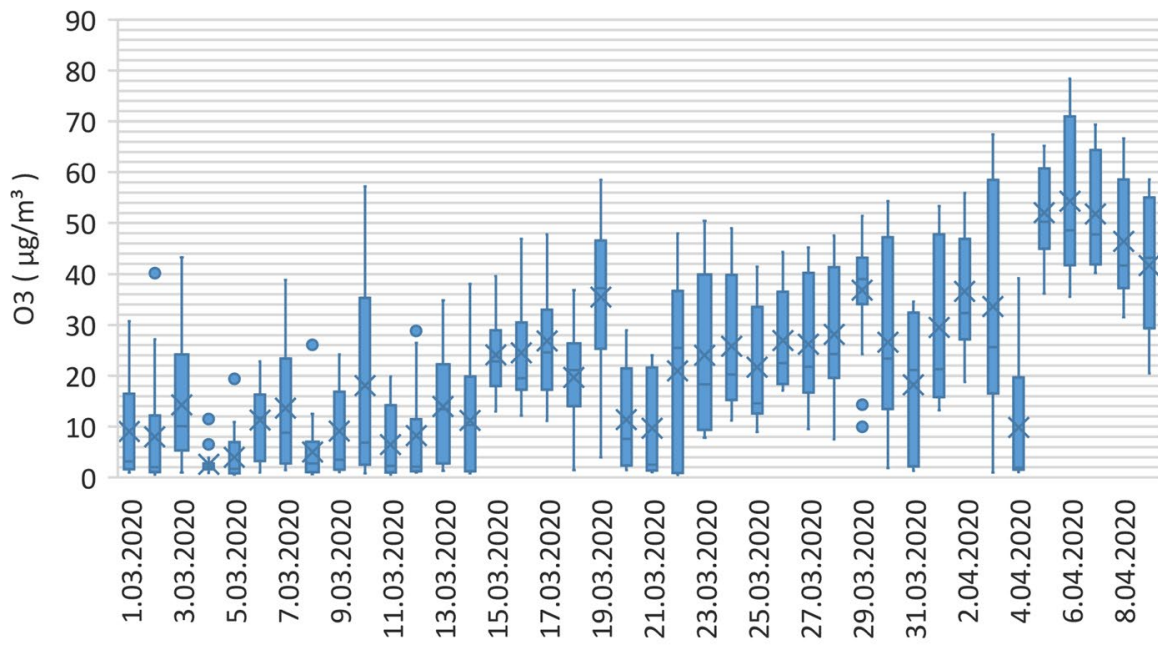

1.03.2020-09.04.2020

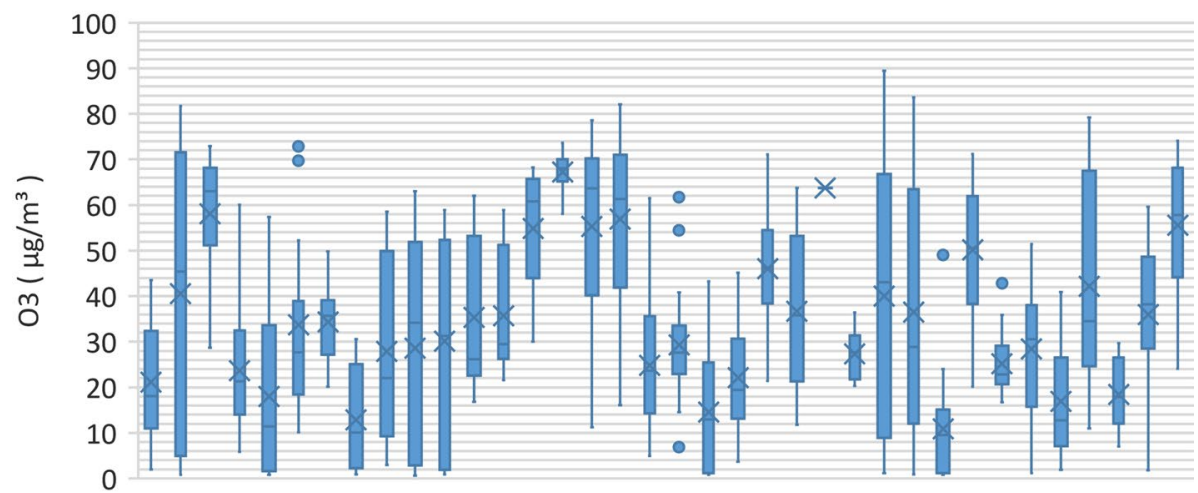

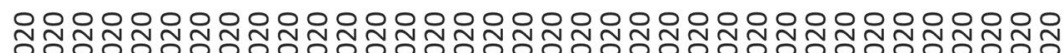

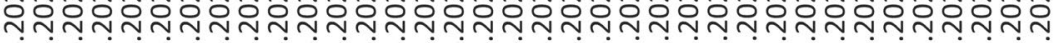

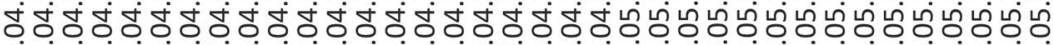

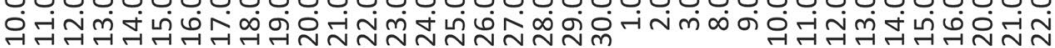

10.04.2020-22.05.2020

Fig. 14 The variation in $\mathrm{O}_{3}$ for Aksaray AMS before and after PL 
Table 16 Variation in hourly $\mathrm{O}_{3}$ concentrations before and during PL

\begin{tabular}{|c|c|c|c|c|c|}
\hline \multirow[b]{2}{*}{ AMSs } & \multicolumn{5}{|l|}{ Europe Side } \\
\hline & Alibeyköy & Aksaray & Bağcılar & $\begin{array}{l}\text { Başakşsehir } \\
\text { MTHM }\end{array}$ & Beşiktaş \\
\hline 1.03.2020-09.04.2020 & 28.69 & 22.38 & 44.75 & 66.38 & 23.41 \\
\hline $10.04 .2020-22.05 .2020$ & 32.86 & 34.96 & 44.00 & 81.70 & 27.76 \\
\hline Variation & 4.17 & 12.58 & -0.75 & 15.32 & 4.35 \\
\hline$\%$ variation & $14.52 \%$ & $56.22 \%$ & $-1.68 \%$ & $23.08 \%$ & $18.57 \%$ \\
\hline AMSs & Esenyurt MTHM & Kağıthane & Sultangazi MTHM & Silivri МТНM & \\
\hline $1.03 .2020-09.04 .2020$ & 10.93 & 11.48 & 29.41 & 66.94 & \\
\hline $10.04 .2020-22.05 .2020$ & 17.67 & 2.45 & 36.50 & 77.48 & \\
\hline Variation & 6.74 & -9.04 & 7.09 & 10.54 & \\
\hline$\%$ variation & $\begin{array}{l}61.67 \% \\
\text { Asia Side }\end{array}$ & $-78.71 \%$ & $24.10 \%$ & $15.75 \%$ & \\
\hline AMSs & Selimiye & Sultanbeyli MTHM & Ümraniye & & \\
\hline 1.03.2020-09.04.2020 & 17.32 & 58.32 & 17.26 & & \\
\hline $10.04 .2020-22.05 .2020$ & 24.44 & 71.39 & 12.29 & & \\
\hline Variation & 7.12 & 13.07 & -4.97 & & \\
\hline$\%$ variation & $41.13 \%$ & $22.41 \%$ & $-28.79 \%$ & & \\
\hline
\end{tabular}

\section{References}

Abdullah, S., Mansor, A. A., Napi, N. N. L. M., Mansor, W. N. W., Ahmed, A. N., Ismail, M., \& Ramly, Z. T. A. (2020). Air quality status during 2020 Malaysia Movement Control Order (MCO) due to 2019 novel coronavirus (2019-nCoV) pandemic. Science of The Total Environment, 729, 139022.

Almond, D., Du, X., \& Zhang, S. (2020). Did COVID-19 Improve Air Quality Near Hubei? (No. w27086). National Bureau of Economic Research.

Anderson, R. M., Heesterbeek, H., Klinkenberg, D., \& Hollingsworth, T. D. (2020). How will countrybased mitigation measures influence the course of the COVID-19 epidemic? The Lancet, 395(10228), 931-934.

Anthony, J. B. (2020a). Implications of telehealth and digital care solutions during COVID-19 pandemic: A qualitative literature review. Informatics for Health and Social Care, 46(1), 68-83.

Anthony, J. B. (2020b). Use of telemedicine and virtual care for remote treatment in response to COVID-19 pandemic. Journal of Medical Systems, 44(7), 1-9.

Asna-ashary, M., Farzanegan, M. R., Feizi, M., \& Sadati, S. M. (2020). COVID-19 Outbreak and Air Pollution in Iran: A Panel VAR Analysis (No. 16-2020). Joint Discussion Paper Series in Economics.

Baykara, M., Im, U., \& Unal, A. (2019). Evaluation of impact of residential heating on air quality of megacity Istanbul by CMAQ. Science of the Total Environment, 651, 1688-1697.

Bokolo, A. J. (2020). Exploring the adoption of telemedicine and virtual software for care of outpatients during and after COVID-19 pandemic. Irish Journal of Medical Science, 1971-, 1-10.

Bontempi, E. (2020). First data analysis about possible COVID-19 virus airborne diffusion due to air particulate matter (PM): The case of Lombardy (Italy). Environmental Research, 186, 109639.

Borrego, C., Martins, H., Tchepel, O., Salmim, L., Monteiro, A., \& Miranda, A. I. (2006). How urban structure can affect city sustainability from an air quality perspective. Environmental Modelling \& Software, 21(4), 461-467.

Cadotte M (2020) Early evidence that COVID-19 government policies reduce urban air pollution. https:// eartharxiv.org/repository/view/345/.

Celik, E., Aydin, N., \& Gumus, A. T. (2014). A multiattribute customer satisfaction evaluation approach for rail transit network: A real case study for Istanbul, Turkey. Transport Policy, 36, 283-293.

Ching, J., \& Kajino, M. (2020). Rethinking air quality and climate change after COVID-19. International Journal of Environmental Research and Public Health, 17(14), 5167. 
Collivignarelli, M. C., Abbà, A., Bertanza, G., Pedrazzani, R., Ricciardi, P., \& Miino, M. C. (2020). Lockdown for CoViD-2019 in Milan: What are the effects on air quality? Science of The Total Environment, 732, 139280.

Dantas, G., Siciliano, B., França, B. B., da Silva, C. M., \& Arbilla, G. (2020). The impact of COVID-19 partial lockdown on the air quality of the city of Rio de Janeiro. Brazil. Science of The Total Environment, 729, 139085.

Debone, D., da Costa, M. V., \& Miraglia, S. G. (2020). 90 days of COVID-19 social distancing and its impacts on air quality and health in Sao Paulo. Brazil. Sustainability, 12(18), 7440.

Fattorini, D., \& Regoli, F. (2020). Role of the chronic air pollution levels in the Covid-19 outbreak risk in Italy. Environmental Pollution, 264, 114732.

Freitas, E.D.; Ibarra-Espinosa, S.A.; Gavidia-Calderón, M.E.; Rehbein, A.; Abou Rafee, S.A.; Martins, J.A.; Martins, L.D.; Santos, U.P.; Ning, M.F.; Andrade, M.F.; Trindade, R.I.F. Mobility Restrictions and Air Quality under COVID-19 Pandemic in São Paulo, Brazil. Preprints 2020, 2020040515 (doi: https://doi.org/10.20944/preprints202004.0515.v1)

Kerimray, A., Baimatova, N., Ibragimova, O. P., Bukenov, B., Kenessov, B., Plotitsyn, P., \& Karaca, F. (2020). Assessing air quality changes in large cities during COVID-19 lockdowns: The impacts of traffic-free urban conditions in Almaty (p. 139179). Kazakhstan.

Li, L., Li, Q., Huang, L., Wang, Q., Zhu, A., Xu, J., \& Azari, M. (2020). Air quality changes during the COVID-19 lockdown over the Yangtze River Delta Region: An insight into the impact of human activity pattern changes on air pollution variation. Science of The Total Environment, 732, 139282.

Mahato, S., Pal, S., \& Ghosh, K. G. (2020). Effect of lockdown amid COVID-19 pandemic on air quality of the megacity Delhi. India. Science of the Total Environment, 730, 139086.

Ministry of Health of the Republic of Turkey. (2020). Covid-19 Current Situation in Turkey. Retrieved from https://covid19.saglik.gov.tr

Muhammad, S., Long, X., \& Salman, M. (2020). COVID-19 pandemic and environmental pollution: A blessing in disguise? Science of The Total Environment, 728, 138820.

Nakada, L. Y. K., \& Urban, R. C. (2020). COVID-19 pandemic: Impacts on the air quality during the partial lockdown in São Paulo state (p. 139087). Brazil.

Otmani, A., Benchrif, A., Tahri, M., Bounakhla, M., El Bouch, M., \& Krombi, M. H. (2020). Impact of Covid-19 lockdown on PM10, SO2 and NO2 concentrations in Salé City (Morocco). Science of The Total Environment, 735, 139541.

Rodríguez-Urrego, D., \& Rodríguez-Urrego, L. (2020). Air quality during the COVID 19 PM2 5 analysis in the 50 most polluted capital cities in the world. Environmental Pollution, 266, 115042.

Rume, T., \& Islam, S. D. U. (2020). Environmental effects of COVID-19 pandemic and potential strategies of sustainability. Heliyon, 9, e04965.

Setti, L., Passarini, F., De Gennaro, G., Barbieri, P., Perrone, M. G., Borelli, M., et al. (2020). SARSCov-2RNA found on particulate matter of Bergamo in Northern Italy: First evidence. Environmental research, 188, 109754.

Sharma, S., Zhang, M., Gao, J., Zhang, H., \& Kota, S. H. (2020). Effect of restricted emissions during COVID-19 on air quality in India. Science of The Total Environment, 728, 138878.

Shrestha, A. M., Shrestha, U. B., Sharma, R., Bhattarai, S., Tran, H. N. T., \& Rupakheti, M. (2020). Lockdown caused by COVID-19 pandemic reduces air pollution in cities worldwide. Preprint. GNU Lesser General Public License (LGPL), 2, 1. https://doi.org/10.31223/osf.io/edt4j

Tayanc, M. (2000). An assessment of spatial and temporal variation of sulfur dioxide levels over Istanbul. Turkey. Environmental pollution, 107(1), 61-69.

The Ministry of Environment and Urbanisation, Retrieved from May 242020 https://cevreselgostergeler. csb.gov.tr/hava-kalitesinde-pm10-ve-so2-ortalamalari-i-85734

Tobías, A., Carnerero, C., Reche, C., Massagué, J., Via, M., Minguillón, M. C., \& Querol, X. (2020). Changes in air quality during the lockdown in Barcelona (Spain) one month into the SARS-CoV-2 epidemic. Science of the Total Environment, 726, 138540.

TUIK, (2020), The Turkish Statistical Institute, Retrieved from May 24, 2020 from, http://www.tuik.gov.tr/ UstMenu.do?metod=temelist

Venter, Z. S., Aunan, K., Chowdhury, S., \& Lelieveld, J. (2020). COVID-19 lockdowns cause global air pollution declines with implications for public health risk. Preprint medRxiv. https://doi.org/10.1101/ 2020.04.10.20060673

Wang, P., Chen, K., Zhu, S., Wang, P., \& Zhang, H. (2020). Severe air pollution events not avoided by reduced anthropogenic activities during COVID-19 outbreak. Resources, Conservation and Recycling, $158,104814$.

Wang, Q., \& Su, M. (2020). A preliminary assessment of the impact of COVID-19 on environment-A case study of China. Science of the Total Environment, 728, 138915. 
World Health Organization. (2020a). Coronavirus disease 2019 (COVID-19) Situation Report-123. Retrieved from https://www.who.int/docs/default-source/coronaviruse/situation-reports/20200522covid-19-sitrep-123.pdf?sfvrsn=5ad1bc3_4.

World Health Organization. (2020b). Report of the WHO-China Joint Mission on Coronavirus Disease 2019 (COVID-19). Retrieved from https://www.who.int/docs/default-source/coronaviruse/who-chinajoint-mission-on-covid-19-final-report.pdf

Xu, K., Cui, K., Young, L. H., Hsieh, Y. K., Wang, Y. F., Zhang, J., \& Wan, S. (2020). Impact of the COVID-19 event on air quality in Central China. Aerosol and Air Quality Research, 20(5), 915-929.

Zambrano-Monserrate, M. A., Ruano, M. A., \& Sanchez-Alcalde, L. (2020). Indirect effects of COVID-19 on the environment. Science of The Total Environment, 728, 138813.

Zhu, Y., Jingu, X., Huang, F., \& Cao, L. (2020). Association between short-term exposure to air pollution and COVID-19 infection: Evidence from China. Science of The Total Environment, 727, 138704.

Publisher's Note Springer Nature remains neutral with regard to jurisdictional claims in published maps and institutional affiliations. 